\title{
Sample Preparation Methods for Pesticides Analysis in Food Matrices and Environmental Samples by Chromatography-Based Techniques: A Review
}

\author{
Elham Sobhanzadeh, Nor Kartini Abu Bakar, Mhd Radzi Abas, Keivan Nemati \\ Department of Chemistry, Environmental Research Group, University of Malaya, Kuala Lumpur 50603, Malaysia \\ Accepted 30 November 2009, Available online 17 December 2009
}

\begin{abstract}
Much attention has been made in pesticide analysis to improve agricultural productivity and control these compounds in food and environmental samples. Different methods have been applied in pesticide analysis, among these; methods based on chromatographic separation with mass spectrometric detection have been extremely useful methods for determination of pesticide residues. Despite employing of powerful instrumental techniques, the risk of interference increases with the complexity of the matrix studied, so sample preparation prior to instrumental analysis is necessary. This article reviews the analytical characteristics of the different sample preparation methods for determination of pesticide residues in food and environmental samples and biological fluids, moreover this study describes advantages, disadvantages and details on the analytical characteristics of the procedure that have been applied recently in different sample preparation methods and their application $\mathrm{s}$ in combination with chromatographic mass spectrometric analysis. This article provides selection of a reliable method which will be useful for the quantitative analysis of pesticide residues in variety of samples based on their evaluation in recent applications.
\end{abstract}

| Sample preparation | Chromatography | Solvent extraction | Pesticide residues | sorptive extraction | mass- spectrometry |

( 2009 Ibnu Sina Insitute. All rights reserved. http://dx.doi.org/10.11113/mjfas.v5n2.294

\section{INTRODUCTION}

In the past decades great advancement has been made in order to achievement high efficient separation of analyte from a sample matrix with high selectivity and sensitivity. Different extraction methods are employed, containing solvent extraction from solids and liquid-liquid extraction from solutions. The solvents may be organic liquids, supercritical fluids and superheated liquids. On the other hand, the extraction liquid may be bonded to a support material. Selectivity can be obtained by altering the extraction temperature and pressure by the choice of extraction solvent or liquid, and the control of $\mathrm{pH}$ and additives such as ion-pair reagents. Poor sample treatment or roughly prepared extract will be invalid the total analysis and will make it impossible to gain a valid result even by use of the most powerful separation method. So the correct sample preparation can be economically valuable as well as analytically important. Sample preparation method is based on the convert of a real matrix into a sample in appropriate format for analysis. Recently the trends for sample preparation methods have been towards:

- The capability to use smaller initial sample sizes.

- better specificity or greater selectivity in extraction

- a more environmentally responsive approach with using a small consumption of solvent and small amount of organic wastes

- improved potential in automation or on-line methods falling manual operations

All extraction methods make using the same basic set of concepts to concentrate the analyte selectivity in one phase, whereas any analyte will be distributed between two phases according to the distribution coefficient, temperature and the relative volumes of the phases. However the extraction rates are based on the migration kinetics and hence are governed by temperature and diffusion rates in the two phases. A balance must often be obtained between the complete extraction of all the soluble organic components and the selective extraction of only the compound of interest. Solid samples can usually be 
prepared, by grinding, mixing, agitating, stirring, chopping, crushing, pressing and pulverizing directly or after drying as enhanced solvent extraction methods, followed by solvent or liquid extraction. After most of these extraction methods the analytes of interest are obtained in an organic or aqueous solution, which then requires concentration or additional clean-up. These extract solutions can then be treated as a liquid samples, Liquid samples can be handled directly such as, quick, easy, cheap, effective, rugged, and safe (QuEchERS)[1], or instrumentally based on heating or agitating of sample such as, pressurized liquid extraction (PLE)[2], microwave assisted extraction (MAE)[3], ultra sonic extraction (USE)[4], supercritical fluid extraction (SFE)[5] by solvent-solvent extraction methods or sorption methods such as, solid-phase extraction (SPE)[6], solid-phase micro extraction (SPME)[7], headspace-solid phase micro-extraction (HS-SPME)[8], stirbar-sorptive extraction (SBSE)[9]. In summary, in most of cases, sample homogenization is involved with an organic solvent often mixed with water by use of homogenizer, blender or sonicator $[10,11]$. The use of a solid sorbent material to extract analytes from a solution developed in the 1980s and is now widely applied to many matrices, including food. A sorbent with strong affinity towards some target analytes will retain and concentrate those compounds from the sample solution. Many sorbents are specifically suited for the extraction of different analytes with various degree of selectivity such as (SPE), (SPME), (SBSE), matrix solid-phase dispersion (MSPD). These methods include both advantages and disadvantages and so application of them depends on the properties of analyte and analytical problems. In this study we focus on application of theses extraction methods in different sample preparation for determining pesticide residues as well as recent applications of chromatography mass spectrometry techniques for analysis and explanation of pesticides structures.

\section{SAMPLE EXTRACTION METHODS}

Since analysis of pesticide residues in solid samples is difficult due to the interfering compounds present in the matrix, sample pre-teatment containing sieving, grinding and drying is often necessary to obtain reliable results. During the last decades, several modern techniques have been purposed to reduce sample handling and toxic waste, consequently to maximize recovery of the analytes and minimize the accompanying interferences by use of appropriate extraction and cleanup procedures. Some of these methods are described in the next sections and their main parameters are summarized in Tables $1,2,3,4,5$.

\subsection{Solvent Extraction (SE)}

Food is a complex non-homogenous mixture of a wide range of chemical substances that makes it hard to isolate and determine the analyte of interest. Therefore, analyses of pesticide residues in food samples are involved with compound interferences in the matrix. To conquer this problem it is necessary to use appropriate extraction method and clean-up process. Many literatures have been reported in the recent years to achieve this objective. Present paper describes summary of these studies in field analyses of pesticide residues with using chromatography MS. A number of solvents have been used for extraction and the most common include ethyl acetate (EtAc) [12-15], acetone [16,17], acetonitrile (MeCN) [18-24], methanol $(\mathrm{MeOH})$ [9,25-27], dichloromethane (DCM) [2,28-29], n-hexane [30,31] and diethyl ether [32]. However it is important to match the polarity of solvent to solubility of analyte, and adding non-polar, water immiscible solvents like DCM or n-hexane to the different polarity solvents to obtain the proper viscosity and modified solvent for extraction. Roos et al. [33] first reported the use of EtAc and sodium sulfate in a multi-residue extraction procedure to eliminate the liquidliquid partition (LLP) step. Whereas Holstege et al. [34] modified the method by addition of acetone, methanol or ethanol in the EtAc to increase the polarity of the solvent system. The ethyl acetate method is also named the on-line extraction method because they omit a separate LLP step. Jianhua et al. [35] studied the application of several organic solvents such as $\mathrm{MeOH}$, chloroform, acetone-n-hexane (1:1 v/v) DCM-MeOH $(9: 1 \mathrm{v} / \mathrm{v})$, and chloroform-MeOH $(1: 1 \mathrm{v} / \mathrm{v})$ for extraction of triazines from sheep liver at $70^{\circ} \mathrm{C}$ for $10 \mathrm{~min}$ of solvent. According to obtained results of recovery the use of chloroform decreased recovery due to the emulsification procedure during extraction. However the recoveries were the highest when $\mathrm{MeOH}$ was used as solvent extraction. To improve extraction time at temperature of $70^{\circ} \mathrm{C}$, with increase of time to 6 min the recovery was increased. Among these solvents $\mathrm{MeCN}$ has some advantages as solvent extraction because $\mathrm{MeCN}$ is a polar solvent, soluble in water. In addition, it can furnish the sufficient extraction for polar and nonpolar pesticides from non-fatty foods due to its hydrophobic property. When $\mathrm{MeCN}$ is employed as solvent extraction, the extracts have a little of co-extractives and facilitate direct analysis by LC-MS or LC-MS ${ }^{2}$ whereas other solvents such as DCM, extracts contain larger amounts of co-extractives so it is possible using $\mathrm{MeCN}$ in the analyses of pesticide residues in complex matrices with different row ingredient and interferences. Appropriate properties of $\mathrm{MeCN}$ distinguish it for use in the QuEChERS technique. Zhou and co-workers [22] compared four organic solvents such as $\mathrm{MeCN}$, methanol, ethanol and acetone for the optimal selection. In the experiments, LC-grade MeCN and methanol was used directly but the analytical-grade ethanol and 
acetone were used after redistilled to remove the impurity before experiments. Between the solvents, it was found that acetonitrile is the best elution performance for analyses of s-triazine herbicides, which caused better separation and great regular peak shape. The lower boiling point of diethyl ether (DEE) [32] rather than EtAC makes it easy to remove with rotary evaporator at less temperature; it has been employed as solvent extraction for post harvest fungicides, phenylphenol, diphenyl (DP), thiabendazole (TBZ), and imazalil (IMZ), in citrus fruits. DEE must be used carefully because it is flammable due to low ignition point and to tend form explosive proxides. Many extractions has been performed with medium-polarity as solvent such as acetone [16,17] and DCM [28-29] but DCM is a carcinogenic to humans. On-column liquid-liquid extraction method (based on classical LLE principle, but assisted by inert solid support), has been tested by Pirard et al. [36], for analyses of different pesticides in honey via LC-MS/MS, as it seems to combine advantages of LLE, SPE and SPME. In LLE technique, MeCN was used as solvent extraction whereas in OCLLE, after agitating of samples with hexane and $\mathrm{MeCN}$, the solution was re-extracted with MeCN. Results proved that extraction by OCLLE can be efficient for a wide range of pesticides, nearly independent of their polarity. The recoveries were between $71 \%$ and $90 \%$. Solvents mixture such as $\mathrm{MeCN}$ saturated with n-hexane [37], $\mathrm{MeOH}$-water [38], acetone-n-hexane [39,40], DCM-MeOH $[41,42]$ and $\mathrm{MeCN}$ saturated with petroleum ether $[43,44]$ have been also used. Because the use of low polarity solvents like EtAc and DCM increase the extracts polarity prior to LC analyses, so some or whole eluate is evaporated before injection to the LC or it is dissolved in a high polar solvent such as MeCN [31], , isooctane [45], acetone [14], mixtures of MeCN with water $[43,44]$ or ultra pure water [46]. SE can be carried out without clean up for extraction of samples free from matrix interferences, although in the most cases clean up of the solvent extracts is necessary to modify quantitative results in subsequent chromatographic analysis. SPE, dispersive SPE [47-57], and classic [4,9,20,59], are the methods most commonly used for this purpose, although gel-permeation chromatography (GPC) [58] and SBSE (enrichment and cleanup) [9] have also been performed successfully. In analysis of fatty samples like fish, after extraction with proper solvent, often low temperature clean up is performed before SPE clean up [59]. In this case, the extraction solution is collected and stored in the freezer at $-24^{\circ} \mathrm{C}$ for $20 \mathrm{~min}$ to freeze lipids. After filtration to remove frozen lipids, the filtered extract is concentrated to follow SPE clean up procedure. Although SE methods have some draw backs such as ,be laborious, be expensive, and they have numerous problems to evaporate large volumes of toxic eluent and consequently high timeconsuming, these methods are accepted and popular for sample preparation due to having advantages like simplicity, robustness, and efficiency. The advent of new modified SE methods in sample treatment field caused the decline of organic solvent consumption, more effective extraction, on-line connecting to analytical methods with high extraction yield. Kinds of these techniques are described in the next section.

\subsubsection{Super-critical Fluid Extraction (SFE)}

Most practical work involved carbon dioxide as a super critical fluid as a potential alternative solvent. In comparison, nitrous oxide proved dangerous because of its oxidizing power and more exotic solvents like xenon were ruled out by their cost. In many ways $\mathrm{CO}_{2}$ is an ideal solvent as it combines low viscosity and a high diffusion rate with a high volatility. The salvation strength increases with temperature, while extraction can be carried out at relatively low temperatures. The high volatility means that simply reducing the pressure and allowing the super critical fluid to evaporate readily concentrates the sample. Using of $\mathrm{CO}_{2}$ reduces organic solvent consumption. It is also inexpensive and nonflammable. In incorporation of various solid-phase sorbents like alumina and octadecilsily-bonded silica at the extraction procedure for purification purpose is one of the advantages of SFE [60]. Principal problem is the relatively low polarity of $\mathrm{CO}_{2}$ which is ideal for PAHs and halogenated pesticides or lipids and fats but unsuitable for most pharmaceuticals and drug samples. It has been popular for solid matrices including powdered plant material, herbal medicines, some foods, but there are some problems associated with liquids like biological fluids, which require immobilizing on a solid support material. The additional of modifiers, such as methanol to the $\mathrm{CO}_{2}$ enables more polar analytes to be extracted and increase the scope of the method. Aguilera et al. [5] evaluated the effects of different factors like supercritical fluid volume, pressure, temperature and static modifier additions on SFE recoveries from spiked wild rice with $6 \%$ olive oil samples with $15 \mathrm{ml}$ of $\mathrm{CO}_{2}$ at $300 \mathrm{~atm}, 50^{\circ} \mathrm{C}$ and $200 \mu \mathrm{l} \mathrm{MeOH}$ as static modifier and using alumina as cartridge. Studies illustrated that in all cases the recoveries without modifier were less than those achieved using methanol as modifier, except the low polar pesticides. Very polar pesticides gave poor recoveries in lack of modifier $(<30 \%)$. On the other hand, when EtAc was used as modifier recoveries were a little higher than those achieved with methanol, except again for polar pesticides that only showed high recovery with $\mathrm{MeOH}$. In another paper this author and co-workers [61] evaluated the retention of fat from wild rice by various sorbent materials (Celite, Extrelut, Hydromatrix, Florisil, and Aminopropyle) employing in-line SFE clean-up procedure under conditions of $15 \mathrm{ml} \mathrm{CO}$ at $200 \mathrm{~atm}$ and $50^{\circ} \mathrm{C}$. Regarding to obtained results amounts of fat extracted per $100 \mathrm{~g}$ wild rice using Celite, Extrrelut and Hydromatrix were undesirable (1.84, 1.80 and 1.62 respectively) whereas for Florisil this amount was reduced up to $0.36 \mathrm{~g}$ and the best results were obtained by use of $1 \mathrm{~g}$ layer of Aminopropyle. 
Rodil et al. [62], employed a useful tool based on a single step extraction and clean up to determine of 15 organohalogenated pollutants in aquaculture samples using aluminium oxide and acidic silica gel in the supercritical extraction cell followed by GC-MS. Selected significant factors such as, extraction temperature $\left(60^{\circ} \mathrm{C}\right)$, pressure, static extraction time $(5 \mathrm{~min})$, dynamic extraction time, and $\mathrm{Co}_{2}$ flow rate $\left(2 \mathrm{ml} \mathrm{min}^{-1}\right)$ were optimized. The Doehlert design, followed by a multicriteria decision-making strategy, was then carried out in order to determine the optimum conditions for the two most important factors: pressure (165 bar) and dynamic extraction time (27 min). After analysis with GC-MS/MS, limit ranges of LODs were 0.01-0.2 $\mathrm{ng} \mathrm{g}^{-1}$ with excellent linearity. However, present information about the ability of on-line clean-up method to remove fat from matrices using SFE is not comprehensive and it needs more studies on sufficient number of analytes and sorbent materials in order to confirm the applicability of this technique for different group of pesticides besides. For example, sorbents, such as alumina, Florisil and silica, can be placed in the extraction cell, or used as a clean-up following extraction to increase selectivity. Sorbents in the extraction cell can also be used for 'inverse' SFE extraction, in which interfering compounds are removed by a weak supercritical extraction fluid, leaving the analyte trapped on the sorbent for subsequent extraction under stronger conditions [63]. In these articles MS detection was employed just for analytical confirmation so there is no information about quantitation analysis such as linearity, precision and LODs in tables.

\subsubsection{Pressurized-Liquid Extraction (PLE)}

This method, which has been commercialized as accelerated solvent extraction (ASE) employs conventional organic solvents at elevated temperatures above the atmospheric boiling points. A restriction or backpressure valve ensures that the solvent remains as a liquid but has enhanced salvation power and lower viscosities and hence a higher diffusion rate. By employing this method, extraction procedure can be carried out in minutes on a smaller sample, considerably speeding up the sample pre-treatment and requires a small fraction of the original solvent volume. An essential feature of the success of this system is the ability to carry out multiple extractions and so move towards automation. The extracts are usually much more concentrated than those obtained by conventional extractions. They could be analysed directly or the solvent could be cooled, and the analyte trapped on glass beads or a cartridge and subsequently extracted into a smaller solvent volume. The raise of temperature causes the increase of extraction rate because the viscosity and the tension of the solvent is decreased therefore the rate of diffusion in to the analyte is increased. The pressure holds temperature of solvent constant lower than its boiling point and affects solvent diffusion into the sample.

PLE method can be carried out in static or dynamic modes, or the combination of both. In the static mod, the sample is placed in a stainless steel vessel containing an extraction solvent. During extraction the rest of solvent is wash out with $\mathrm{N}_{2}$ into a collection vial. In second system solvent extraction is pumped through the sample but with high solvent consuming and diluting of the extraction. Anhydrous sodium sulfate, diatomaceous earth, cellulose or sorbent material can be used in clean-up step. In order to optimize the conditions, statistical experimental design procedures are used to reduce the number of experiments. [64]

Modifiers can be added to the extraction solvent. For instance water modified with a surfactant (sodium dodecyl sulphate) was used to extract PAHs from fish tissues. [65] Tomomi et al. [13] used a simple one step extraction and cleanup by PLE under optimized conditions (extraction tempreture: $100^{\circ} \mathrm{C}$, extraction pressire: $11 \mathrm{MPa}$, static extraction time: 10 min, extraction cycle time:once, solvent flush volume: $6.6 \mathrm{ml}$ ) for determination of six insecticides, a fungicide and a herbicide in vegetables via GC-MS. Between several drying materials, such as anhydrous sodium sulfate, alumina, silica gel, florisil and graphitized carbon, the last one was reported desirable, so graphitized carbon was used to remove the coextracted water because it produced a transparent and colorless solution with mean recovery of $95 \%$. In this study the extracts had a dark green color when alumina (mean recovery: 92\%) was used as the clean-up agent and the result were similar to florisil (mean recovery: 76\%) and silica gel (mean recovery:82\%). In evaluation of amount of graphitized carbon, with reduction of graphitized carbon from $12 \mathrm{~g}$ to $6 \mathrm{~g}$, the color of the resulting increased from colorless to dark green. The overall recovery obtained for analysis of 8 pesticides was ranged 71-103\%. By contrast of Blasco et al. [12] that reported, the obtained extracts by PLE extraction after the dispersion of fruit samples with acidic alumina They reported that anhydrous sodium sulfate instead of alumina produced an extract with a cloudy and strong color. However, they did not evaluate the cleanup effects of the extraction procedure, because they used the materials as a solid support material or a drying material. Izabela et al. [66] developed and validated the simultaneous extraction and in situ clean-up of polychlorinated biphenyls (PCBs, OH-PCBs, $\mathrm{MeSO}_{2}$ - $\mathrm{PCBs}$ ) and their metabolites in small tissue samples by PLE method. A mix of fat retainer and diatomaceous earth pre-extracted in a short PLE cell of the combined extraction and in situ cleanup to prevent cell memory effects. After tissue extractions, the pre-extracted diatomaceous earth was eliminated from the PLE cell by mixing of liver from non-PCB exposed rats. After spiking the PLE cells were extracted twice under the same conditions of pre-extraction. Separation of different fractions was carried out using different physicochemical properties of selected pesticides based on the procedure defined by Hovander et al. [67] Followed by optimization of PLE parameters, 
temperature (60-120), pressure (6.9-13.8 MPa, 1000-2000 psi) and the length of static cycle (1-9 min) were investigated by using of extraction solvent containing hexane-dichloromethane-methanol (50:45:5 v/v). Validation of PLE-based method under optimized conditions (hexane-dichloromethane-methanol; 48:43:9 v/v, temperature of $100^{\circ} \mathrm{C}$, pressure of $1500 \mathrm{psi}, 6$ min heating time, 1 static cycle of $5 \mathrm{~min}$ and a $60 \%$ cell volume flush) was performed by comparison of extraction method described by Jenson et al. [68] also by verifying its linearity and repeatability. The Jensen method required more laborintensive extraction with different solvent combinations of increasing polarity andclean-up steps with additional columnclean-up steps for both PCBs and MeSO2-PCBs in comparison with the PLE method described by Izabela that required a single, automated PLE extraction step. For lipid containing samples, further clean-up is usually required and Gomez et al. [69], investigated the use of several sorbents and concluded that Florisil produced the cleanest extracts for their samples. An alternative approach is to perform a preliminary PLE with a non-polar solvent to eliminate the hydrophobic compounds prior to extraction of the analytes of interest. The use of pressurized fluids in comparison with soxhlet extraction have the advantages of reducing solvent consumption and extraction time although they need using expensive specialized equipment and clean up procedure is necessary after extraction.

\subsubsection{Microwave Assisted Extraction (MAE)}

To make easy sample pre-treatment, there have been tests of new extraction procedures based on instrumental techniques such as MAE with smaller amounts of matrix and solvents consumption and rapid extraction has been investigated since 1986 [70]. The key advantages of this method are the low temperature necessity, high extraction efficiency, automation, the chance of simultaneous extraction of different sample without interference, small a mounts of matrix and solvent and rapid extraction. By contrast in other heating methods, the extraction vessel does not need direct heating and so the extraction time required decreases. Additional clean up step and the lack of selectivity in comparison with SFE, are the advantages of MAE method. In conventional extraction techniques consuming of more solvent volume to solid matrix mass usually increases recovery. However, in MAE a higher ratio of solvent may lead to lower recoveries, probably because of inadequate stirring of the solvent by the microwaves. It is only employed for extraction of compounds that are thermally stable because increase in temperature during extraction may lead to degradation, so in such circumstances the power selected during MAE must be set correctly to avoid excessive temperatures. Antioxidants and preservatives can be extracted with this technique if the matrix is low in fat. This technique can be used to extract herbicides in soil, and polycyclic aromatic hydrocarbon (PAHs) in sediments. Microwave extraction has also been combined with PLE for the extraction of polymers. Alternatively, sonication can be used to enhance extraction and this has been applied for the extraction of organophosphorus pesticides. [71]. MAE technique like SFE and PLE provides simple conditions for working at high temperatures and pressures, which intensely enhance the speed of extraction procedure. On the contrary, traditional techniques for solid matrices, such as the well-known Soxhlet extraction, together with shaking and sonication [72], which can also provide efficient extractions with low investment, seem to demand decreasing attention due to their drawbacks: long extraction times (especially for Soxhlet), relative high solvent consumption, occasional need of a clean-up step and possible repeated extractions in the case of sonication. Two of these methods have been used, less in fashion in recent periods but of low cost, are the object of the proposed examples. The main advantages of microwave pretreatment are the low temperature requirement, high extraction efficiency, complete automation, and the possibility of simultaneously extracting different samples at the same time without interference. On the other hand, the extraction vessel is not heated directly, which reduces the extraction time required.

Extraction of triazine herbisides from environmental samples by MAE method has been studied broadly. Cheng et al. [35] presented a multi-residue method developed for determination of trazine herbicides (simazine, atrazine, propazine and prometryn) in sheep liver by MAE using $\mathrm{MeOH}$ as solvent extraction. This solvent has high dielectric constant to adsorb microwave energy efficiently; however non-polar solvents such as hexane and toluene, are not potential solvents for MAE, (but their extracting selectivity and efficiency can be modulated by using mixtures of solvents for example hexane acetone [73]). They optimized the MAE operation parameters such as type and volume of solvent, time and temperature of extraction in order to increase the extraction yield. First $10 \mathrm{ml} \mathrm{MeOH}$ was added to the extraction vessels placed into the microwave sample preparation system at $70^{\circ} \mathrm{C}$ for $6 \mathrm{~min}$ after cooling in the room temperature and filtration, the extract was washed three times with $5 \mathrm{ml} \mathrm{MeOH}$ each time. The extraction was performed three times with $10 \mathrm{ml}$ petroleum ether each time. After separation of layer of ether, extraction was carried out three times with $1 \mathrm{ml}$ of $0.1 \% \mathrm{NaCl}, 9 \mathrm{ml}$ water and $10 \mathrm{ml}$ chloroform per time. After distillation of all solutions to dryness and reconstitution of residues with $5 \mathrm{ml} \mathrm{MeOH}$, the solution was transferred to the column containing anhydrous sodium sulfate and aluminum oxide. Regarding to obtained recoveries, using chloroform as extraction solvent resulted in emulsification and a decrease in recoveries. The results were desired (upper than 90\%) when the extraction time increased from $2 \mathrm{~min}$ to $6 \mathrm{~min}$. Different clean-up procedures has been carried out after MAE extraction such as SPME [74] and disposable SPE cartridge packed with $\mathrm{C}_{18}$, silica and ion exchange material $[41,75]$. 


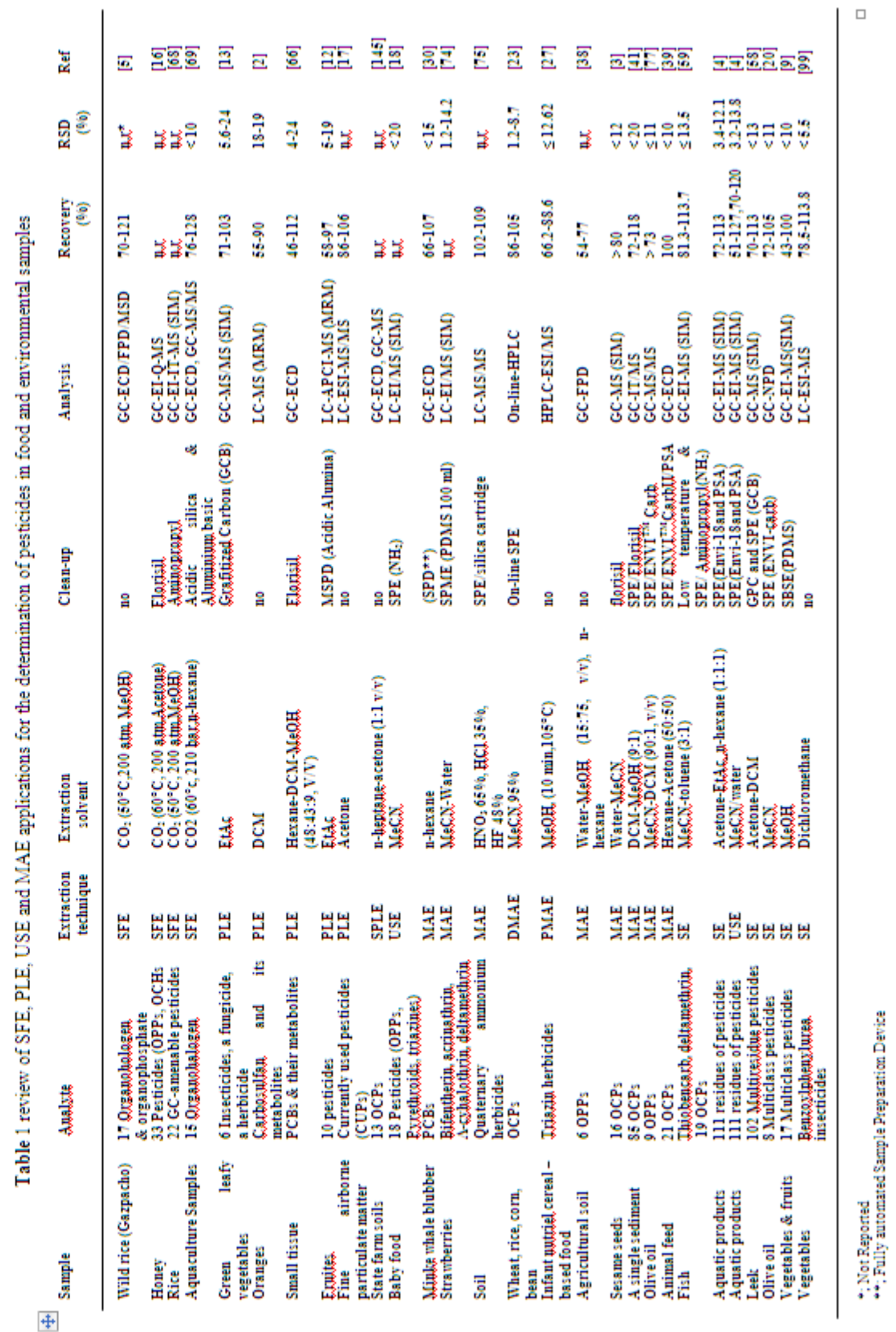


Among many studies that was done on different extraction method coupled with chromatographic techniques and MS to analyze and determining of pesticide residues in foods, a few studies has been reported by using MAE coupled with both chromatographic systems and MS. The reason might be the requirement of sample filtration and clean-up steps after extraction, something that is impossible to circumvent, in comparison with SFE and PLE method, in which on line clean-up and filtration are possible. Sanusi and assistants [74] employed focused microwave-assisted (FMAE) coupled with SPME and GC-MS for extraction and analysis of pyrethroid residues in strawberry respectively. To improve the conditions of FMAE-SPME they added co-solvent $(\mathrm{MeOH}, \mathrm{MeCN}$ or $\mathrm{EtOH})$ to the extraction solution instead of pure water to increase the transfer of the analytes into the solution analyzed by SPME and compared the observed signal. The results illustrated that, the observed signal by addition of the co-solvent was better than the use of pure water. Among three co-solvents, $\mathrm{MeCN}$ was most sensitive. The obtained LODs were according to MRLs. The second study reported by Iglesias et al. [39] that developed an analytical method based on MAE with hexane-acetone $(50: 50 \mathrm{v} / \mathrm{v})$ as solvent extraction, SPE clean up with three different sorbents (alumina/ ENVI ${ }^{\mathrm{TM}}$-Florisil, ENVI ${ }^{\mathrm{TM}}$-Carb and ENVI ${ }^{\mathrm{TM}}$-Carb II/PSA) and Hexane-EtAc (80:20 $\mathrm{v} / \mathrm{v}$ ) as eluent for determination of organochlorine pesticides in animal feed. The analytes were determined by GC-ECD and quantified via GC-MS. According to obtained results ENVI ${ }^{\mathrm{TM}}-\mathrm{Carb}$ and $\mathrm{ENVI}^{\mathrm{TM}}-\mathrm{Carb} \mathrm{II} / \mathrm{PSA}$ furnished colorless eluates with lower interferent compounds in $\mathrm{ENVI}^{\mathrm{TM}}$-Carb II/ PSA chromatograms, so this system was employed for purification of extracts. The recoveries $(100 \%)$ were similar to those achieved with soxhlet extraction. Validation method was performed with the analysis of certified reference material (CRM-115 BCR), the results were according to certified values. The range of LODs were between 2 and $19 \mu \mathrm{g} / \mathrm{kg}$ and LOQs ranged from 5 to $37 \mu \mathrm{g} / \mathrm{kg}$ corresponding to the MRLs and below. Jingyan et al. [27] described using of pressurized microwave-assisted extraction (PMAE) without clean-up step for determination of triazine herbicides in infant nutrient cereal-based foods coupled with HPLC-ESI/MS. After improvement of key factors of PMAE like extraction solvent, extraction temperature and extraction time, the method was validated with atmospheric pressure microwave assisted extraction (AMAE), ultrasonic extraction (UE) and soxhlet extraction (SE). The obtained recoveries (66.2-88.6\%) from the proposed method were better with more efficiency, faster and without clean-up procedure. To optimize solvent extraction, among different solvent such as $\mathrm{MeOH}, \mathrm{MeCN}$, acetone, acetone-n-hexane (1:1, $\mathrm{v} / \mathrm{v})$ and $\mathrm{MeOH}-\mathrm{DCM}(1: 1, \mathrm{v} / \mathrm{v})$, the required microwave radiation time to reach a temperature of $85^{\circ} \mathrm{C}$ by using $\mathrm{MeOH}$ was less (241s). The ability and specific heat of solvent for absorption of microwave energy seemed to affect the temperature.

Edwar et al. $[38,76]$ worked on the determination of selected organochlorine pesticides in agricultural soil by MAE. First time, they used water-MeOH as modifier for desorption and simultaneous partitioning with n-hexane (MAEP) by use of GC-FPD. In second time, they employed MAE coupled to SPE and GC-ECD for the determination of pesticides mentioned in olive oil. In this study MeCN-DCM was used as solvent for LLE, while ENVI Carb and DCM were used as SPE cartridge and elution solvent respectively. Confirmation was performed by GC-MS/MS. In first study, olive oil was used as matrix mimic in order to optimize GC-FPD signals and improve the extraction method. By addition of $\mathrm{KHPO}_{4}$ to the mixture of water- $\mathrm{MeOH}$, the recoveries were increased (up to $73 \%$ ) compared with using the mixture of water-MeOH alone with recoveries were 54-77\%. However, in last study, when MeCN was used as solvent for partitioning of LLE alone recoveries ranged 62-99\% and adding DCM to the extraction solvent caused the increase of recoveries. Most MAE applications to date have been for extraction of environmental samples, as for the MAE coupled with GC-MS or LC-MS, it needs more investigations in the next few years. Table 1 illustrates operational characteristics of instrumental solvent extraction (SFE, PLE, USE and MAE extraction) methods for determination of pesticide residues in different samples.

\subsubsection{QUEChERS}

QuEChERS is a quick and convenient replacement for LLE which offers a great quality results with less labor-intensive sample preparation steps and low consuming solvent and glassware. QuEChERS stands for quick, easy, cheep, effective, rugged and safe and as the newest-generation method for analysis of pesticide residues in food matrices. These characteristics are evident in its name [77]. This method offers good features for the analysis of polar pesticides.

The main technique consists in extraction of a homogenized sample by hand-shaking or vortex rotary with the same amount of acetonitrile to give a final extract adequately concentrated due to the lack of need for solvent evaporation. A mixture of $4 \mathrm{~g}$ anhydrous mangnesium sulfate $\left(\mathrm{MgSo}_{4}\right)$ and $2 \mathrm{~g}$ sodium chloride $(\mathrm{NaCl})$ which provides well-defined phase separation without dilution and dangerous non-polar organic solvent, are added to the sample by mixing to drive partitioning of the analytes between the aqueous residue and the solvent. after shaking and centrifugation, clean up and elimination of residual water is carried out simultaneously using a rapid technique, called dispersive solid phase extraction (DSPE), in which a primary-secondary amine (PSA) adsorbent (a weak anion-exchanger which removes fatty acids, sugars and other matrix co-extractives that form hydrogen bonds) and extra anhydrous $\mathrm{MgSo}_{4}$ are blended with the sample extract. DSPE is based on SPE method, but the adsorbent is added directly to the extract and the clean-up is simply carried out by shaking and centrifugation. This method takes lower time than traditional SPE and simultaneously enables the removal 
residual water and a lot of polar matrix components, such as organic acids, polar pigments and sugar. So MeCN is selected solvent for successfully extraction of kinds of pesticides from various food matrices by use of QuEChERS [47-57].

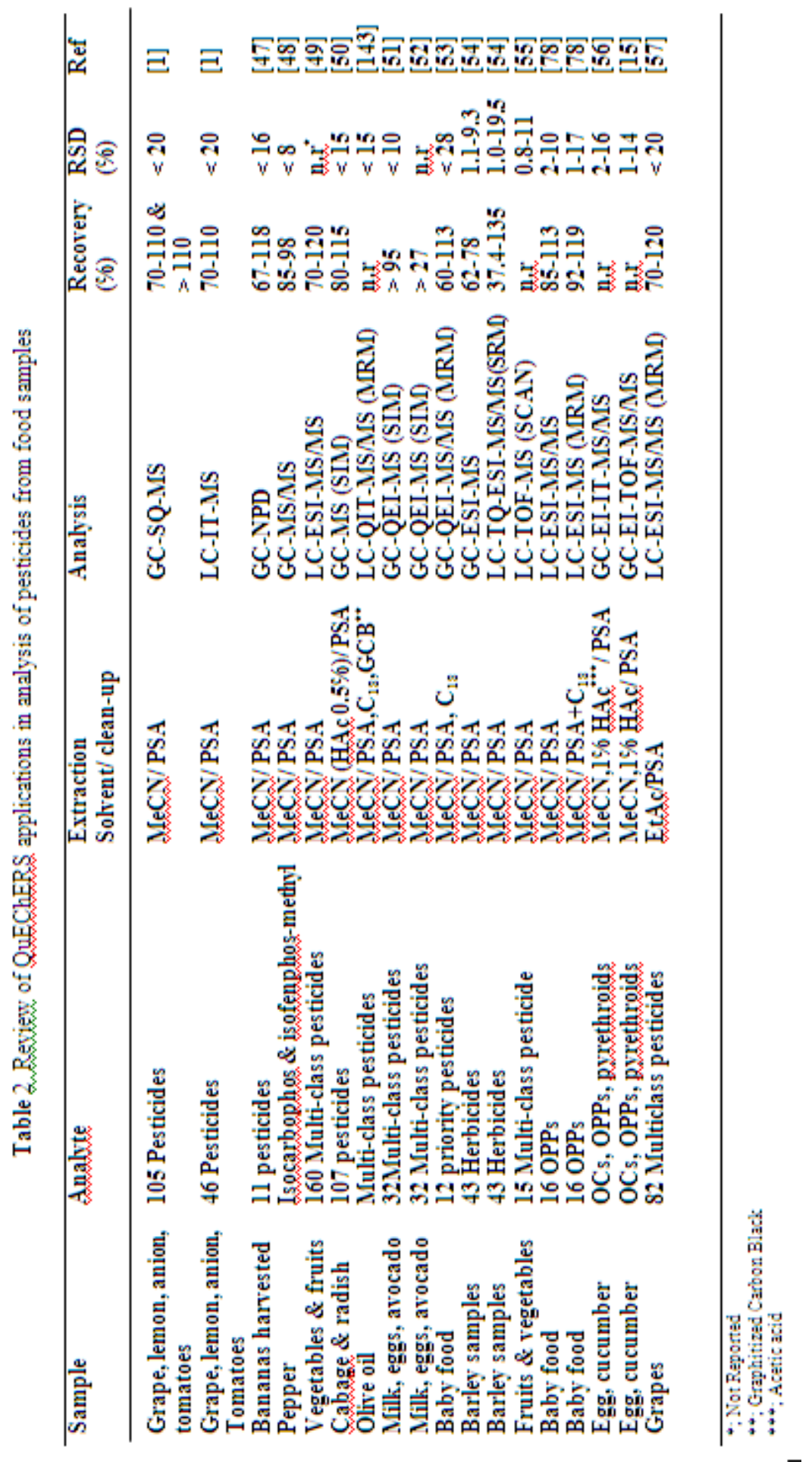


The use of two mixed adsorbents like $\mathrm{C}_{18}$ and PSA has been evaluated by Leandro and assistants [78] in extraction of OPPs and transformation products from baby food using QuEChERS and DSPE clean up step. Obtained recoveries were close to $100 \%$, when $50 \mathrm{mg}$ of PSA was used. Observed results were undesirable when the mixed adsorbents $(50 \mathrm{mg}$ PSA $+100 \mathrm{mg} \mathrm{C}_{18}$ ) or only $\mathrm{C}_{18}$ were used depending on the matrix and the class of the pesticide analysed. So PSA was chosen as adsorbent in analyses of these class of pesticides by HPLC-MS/MS and UPLC-MS/MS because it prepared a clean extract, and peak shape with improved signal-to-noise ratio $(\mathrm{S} / \mathrm{N})$ in comparison with crude extracts. In another study this research group [53] investigated the effects of different amounts of $C_{18}(100-300 \mathrm{mg})$ with $50 \mathrm{mg}$ PSA in quantity of co-extractives remained after evaporation of solvent. The lack of reproducibility among the diverse range of matrices was observed when $100 \mathrm{mg} \mathrm{C}_{18}$ was used. On the other hand, non-linear calibration plots and low recoveries were resulted when $300 \mathrm{mg} \mathrm{C} \mathrm{C}_{18}$ was tested. However, cleaner extracts, improved $\mathrm{S} / \mathrm{N}$, and satisfactory calibration plots were obtained when the range of 100-200 $\mathrm{mg} \mathrm{C}_{18}$ was consumed as adsorbent. Recently Milagros and co workers [48] described two methods based on GC-MS (SIM) and GC-IT-MS/MS (SRM) for identification, confirmation and quantification of two insecticides in pepper samples by use of QuEChERS. Can was used as extraction solvent and clean up step was performed by dispersive solid-phase extraction using PSA as sorbent material. Average recoveries were in the range of $85-98 \%$. In brief, No significant differences on the performance of both methods were noticed in terms of sensitivity and limit of detection, although the unambiguous confirmation capabilities provided by MS/MS cannot be achievedwith a single quadrupole analyzer. The potential of the proposed methods was demonstrated by analyzing real samples with excellent selectivity and sensitivity, thus enabling the unambiguous identification of trace levels of these insecticides in pepper samples. The advantages of QuEChERS method containing high recovery, high sample yield, accurate results, low solvent and glassware consumption, lower labor and bench space, less reagent costs and rugdness. The main drawback of this method is that for 1 g sample per milliliter of final extract the concentration of obtained extracts using this method is lower than concentrated extracts achieved by the use of most conventional procedures. Hence, the final extract must be concentrated to a more extent to provide the high sensitivity and to obtain the limits of quantification (LOQ) desired. Table 2 reviews the applications of this method for determination of pesticide residues in variety of food samples.

\subsection{Matrix solid-phase dispersion (MSPD)}

In order to analysis of semi-solid and solid food matrices and overcome the serious restrictions of SE and SPE methods and achieve high efficiency especially in environmental analysis, in 1989 Barker and co-workers [79] described a procedure for the extraction of target analytes in solid matrices. MSPD enables disruption and dispersion of analytes simultaneously on a solid support, thereby creation a proper chromatographic compound in order to extraction of analytes from the dispersed sample. Reversed phase sorbent materials such as octyl-bonded silica $\left(\mathrm{C}_{8}\right)$ and octadeyl-bonded silica $\left(\mathrm{C}_{18}\right)$ are the most commonly used adsorbents, because of the lipophilic characteristics of them that cause a good disruption and dispersion. In this method, the adsorbent is mixed with the sample by a mortar and pestle or a related mechanical device. MSPD allows the extraction of pesticides from homogenously dispersed target samples in a solid support, such as florisil and silica. The homogenized mixture is placed in a column and analytes are selectively eluted with solvents. Thus, sample extraction and clean-up are performed in the same step. This approach can be used for screening pesticides or other chemicals in different biological matrices and could be useful in the environmental bio-monitoring programs. The application of extraction organic solvents are minimized but not completely eliminated, so organic solvent is unable for extraction of target analytes from matrices and this fact causes the necessity of clean-up step. Recently, in MSPD technique hot water has been used as solvent extraction for development of LC-MS in analysis of different food stuffs such as milk, vegetables, tissues, eggs and baby food. Juan et al. [44] reported the use of MSPD after preliminary LLE by MeCN saturated with petroleum ether for analysis of herbicides in olive oil by LC/TOF-MS. The obtained extracts from LLE step was homogenized with aminopropyl-bonded silica as dispersant sorbent by means of a glass mortar and pestle. The mixture was then transferred into the minicolumn containing packed florisil, that it was connected to the vacuum in order to cleanup procedure. After elution with $\mathrm{MeCN}$ with the flow rate of $3 \mathrm{~mL} \mathrm{~min}^{-1}$, the extracts were evaporated and dissolved in MeCN-water $(1: 1, \mathrm{v} / \mathrm{v})$ perior to LC/TOF-MS. Obtained recoveries were $81-111 \%$. Numerous adsorbents with different selectivity are available that can be selected based on the analytes of interest, type of matrix and interferences. The use of MSPD in food analysis has been reported using sorbents, such as, silica [80], Florisil [81-83] and C18 or C8 bonded silica [37,84]. Inert adsorbents, for example diatomaceous earth $[85,86]$ and sand $[87,88]$, instead of reversed or normal-phase dispersant have been successfully used in analysis of pesticides in fruit juices, fatty foods and tissues, because they enable early elution of interferences that would not be retained by any adsorbent during elution of the target analytes. The combination of sand as dispersant with water as elution solvent for polar analytes in any type of matrix enables almost quantitative recoveries and analysis of extracts directly with LC techniques. Recently, it has been proved that replacement of C18 by amino-propyl silica or primary and secondary amine (PSA) sorbents leads to cleaner extracts from complex fatty 
samples, e.g. olives [43,44,89-91]. It seems that the weak anion-exchange character of amino materials is responsible for this better selectivity, due to more effective retention of the fatty acids present in biological samples.

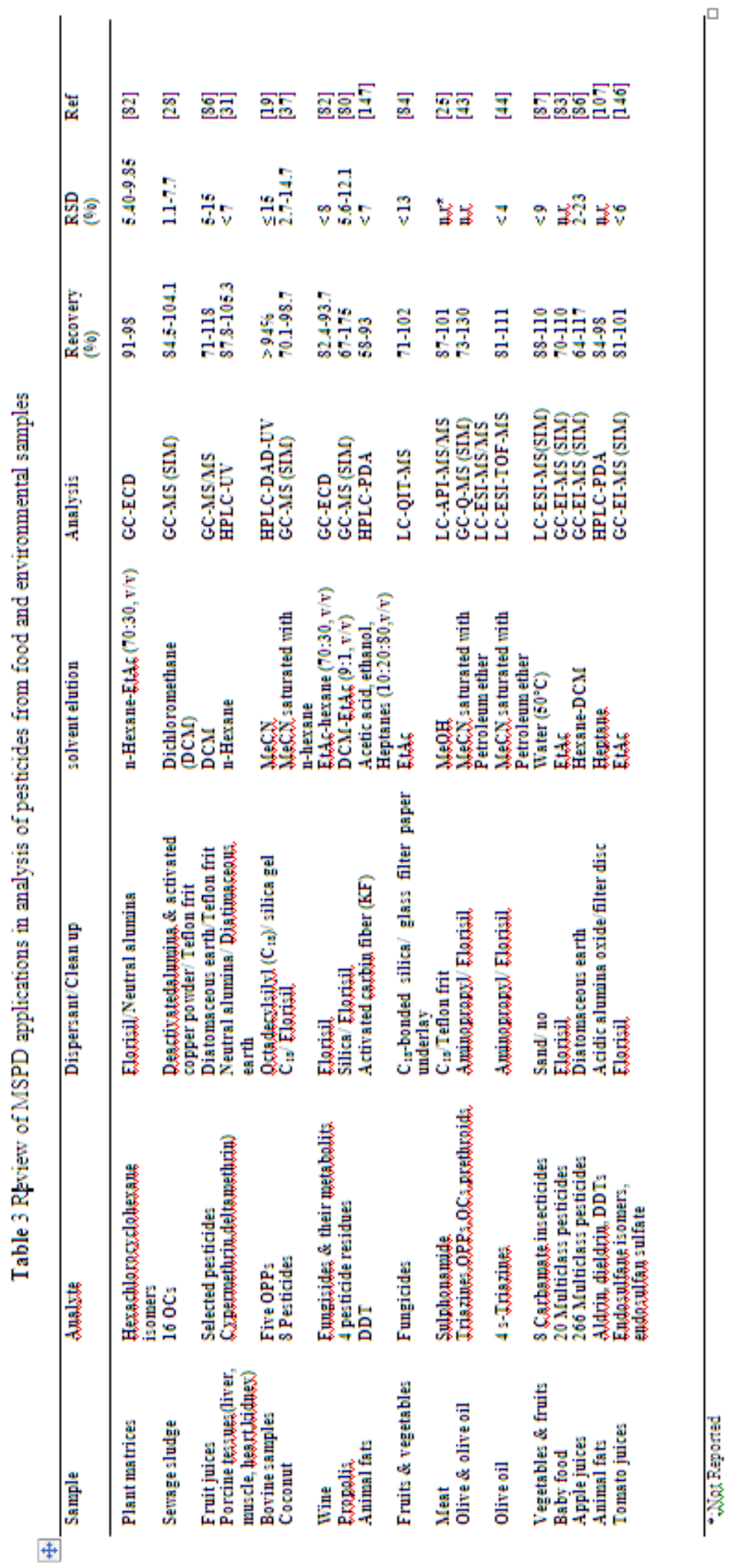


Reversed-phase octadecyl silica ( $\left.\mathrm{RP}_{-} \mathrm{C}_{18}\right)[92,93]$ is another commonly used dispersant because of its high reactivity that leads to the modification of its surface by chemical reaction. Another important parameter in MSPD process is the selection of extraction solvents that depends on the analyte polarity. Apolar solvents such as hexane, DCM, or mixture of both can be used in extraction of non-polar compounds, whereas medium or high polar substances can be recovered using polar solvents such as acetone, MeCN, EtAc, water-ethanol or methanol. Maria et al. [37] determined pesticides in coconut based on MSPD under optimized conditions such as type and amount of solid-phase $\left(\mathrm{C}_{18}\right.$, alumina, silica-gel and florisil), selection of eluent (DCM, MeCN, EtAc, acetone, n-hexane and n-hexane-water (1:1 v/v)) by GC-MS (SIM). The best result obtained when $\mathrm{C}_{18}$, florisil and acetonitrile saturated with n-hexane were used as dispersant sorbent, clean-up sorbent and eluting solvent respectively. Average recoveries were between 70.1 and $98.7 \%$ with RSD from 2.7 to $14.7 \%$ except for two pesticides. Marina et al. [85] developed a rapid and sensitive LC-MS/MS method for the analysis of selected pesticides in fruit juices based on MSPD extraction process by use of diatomaceous earth as dispersant and DCM as eluent. In order to avoid the application of chlorinated solvents like DCM, other extraction solvents such as EtAc and MeOH were tested for all selected pesticides. The results of recoveries were undesirable when EtAc was used, however the use of $\mathrm{MeOH}$ as solvent extraction required an additional clean-up step, so DCM was used as extraction solvent. The effects of $\mathrm{pH}$ were studied over the range 2-8 and the highest recoveries were obtained with $\mathrm{pH}$ - value adjusted to 6 . The obtained recoveries were between 71 and $118 \%$ with RSD in the range of 5-15\%. One paper [31], devoted an effective MSPD method for determination of cypermethrin and deltamethrin in porcine tissues with a neutral alumina-based MSPD column and HPLCUV using reversed-phase $\mathrm{C}_{18}$ column. In order to obtaining of high elution efficiency, dissimilar solvents polarities (nhexane, n-hexane-EtAc (1:1), n-hexane-DCM (1:1), EtAc and n-hexane-acetone) was tested. When EtAc, acetone and DCM were used as solvent extraction, a great number of interferences were extracted into the eluate. Whereas n-hexane is a weak polar solvent, a mixture of it with other solvents has intermediate polarity and so n-hexane $(20 \mathrm{~mL})$ was used as eluent solvent. The ratio of mobile phase was optimized and acetonitrile-water $(85-15, \mathrm{v} / \mathrm{v})$ was selected as mobile phase. The recoveries were between 83.5 and $109 \%$. When the traditional method is compared with the MSPD-SSEC method, the MSPD-SSEC method reduces sample contamination during the procedure, and decreases the amount of organic solvent needed. Fernanda et al. [80] compared and evaluated a variety of dispersant materials such as $\mathrm{C}_{18}$, alumina, silica and florisil as for the amount of solid-phase and eluent such as n-hexane, DCM, n-hexane-DCM (8:2 and 1:1, v/v), DCM-EtAc (9:1, $8: 2$ and 7:3, v/v) in analysis of different pesticide residues by GC-MS. The obtained results were excellent when $1.0 \mathrm{~g}$ silica and $1.0 \mathrm{~g}$ florisil and DCM-EtAc $(9: 1, \mathrm{v} / \mathrm{v})$ were used as dispersant, clean-up sorbent and elution solvent respectively. The main factors in selection of elution solvent are, its Capability to selectively and quantitatively recover target analytes and its compatibility with the subsequent determination technique, harmlessness, low cost, low consumption solvent, and environmental friendliness are also desirable attributes. Hot water has been used for eaxtraction of polar to moderate polar contaminants from solid matrices because of the drop of its polarity with increase the temperature [94]. Extraction with high temperature water is carried out at atmospheric or elevated pressures. Low toxic solvent consumption, reducing cost and analysis time, simplifying and speeding up the sample treatment procedure, increasing reliability and in most cases integrating of extraction and clean-up in a single step are the advantages of this technique. Table 3 shows the review of MSPD applications in analysis of pesticide residues from different samples.

\subsection{Sorptive Extraction Methods}

\subsubsection{Solid-Phase Extraction (SPE)}

Solid phase extraction is the extensively accepted as an alternative extraction-clean up method including a preliminary LLP step, although it can be used without this step, which involves the use of disposable cartridges to trap analyte and separate them from the bulk of the matrix. The adsorbent materials in SPE procedure play a significant role in achievement grater enrichment efficiency and lower cost of organic solvents. Many types of adsorbents such as florisil [95], alumina, magnesium silicate, graphitized carbon and oasis HLB [96,97], adsorbents with weak anion-exchange and polar capabilities $\left(\mathrm{NH}_{2}\right)$ [42], polystyrene-divinylbenzene supports [98] and $\mathrm{C}_{18}$ [15,92,99], SWCNTs and MWCNTs [100,6,14,21,29], mixed mode phases, bamboo charcoal [22], that have been shown to be valuable adsorbents for sample enrichment and clean-up of a variety of pesticides in food matrices and environmental samples; the most commonly used material, however, is the reversed-phase octadecyl silica (RP-C18) [92,93,45,101] because it is sufficiently reactive to enable its surface to be modified by chemical reaction and yet sufficiently stable to enable its use with a wide range of solutions. Silica is reactive enough to permit its surface to be modified by chemical reaction and yet stable enough to allow its use with a wide a range of solutions. The introduction of the disposable pre-packed SPE cartridges had major effects on methods for the examination of the analysis in solution. The SPE cartridge introduced two critical factors, standardization and hence greater reproducibility, and a much wider range of phases, importantly including reversed-phase and ion-exchange materials enabling aqueous solutions to be treated and additional trapping mechanisms to be utilized. 
A wide range of phases means that polarity, hydrophobicity or ionization can be used as trapping mechanisms and the sample matrix may now be non-polar or aqueous. Once trapped, the analyte can be released into a small volume of an extraction solvent by altering the polarity or $\mathrm{pH}$. Although the cartridges are single use and disposable and thus present a significant consumable cost, this has been claimed to be much lower than the cost of chemicals and manpower needed for the corresponding traditional solvent extraction methods. Method development in SPE is usually accomplished by investigating $\mathrm{pH}$, type and solvent strength of the sample matrix, polarity and flow rate of the elution solvent, and physicochemical characteristics of the adsorbent bed. Sample $\mathrm{pH}$ can be crucial to obtaining high pesticide retention on the adsorbent. Occasionally, therefore, sample $\mathrm{pH}$ modification can be necessary to stabilize the pesticides and increase their absorption by the solid phase [102]. Recent use of high flow-rates through extraction cartridges has been claimed to give improved extraction [103]. The disposable cartridges reduced the handling of body fluids, such as urine and blood, and hence the biohazard to the operator is minimized. SPE method has been widespread applied for determination of contaminants in environmental samples such as, river waters and sewage outflow, where large volumes of very dilute solutions have to be extracted $[21,22,98,100]$. With conventional solvent extraction, large volumes of sample solution had to be manipulated to obtain sufficient analytes for assay. With SPE cartridges, the sample is simply pumped through the SPE bed and the analytes are eluted with a small volume of organic solvent. Eluent selection is based on high performance, low volume consuming, low toxicity, non-interferences with compounds and compatibility with the chromatographic system used. In order to optimization of selected method, extraction conditions such as time or range of flow rate, temperature of extraction, effect of solution $\mathrm{pH}$ and sample volume must be considered. Hongyun et al. [100] used single-walled carbon nanotubes disk as sorbent material and $\mathrm{MeCN}$ as eluent in SPE method for extraction of sulfonylurea herbicides in water samples by HPLC-DAD. This research group demonstrated that when the selected analytes (sulfonylurea herbicides) are weak acids the solubility of them in water is increased drastically with the solution $\mathrm{pH}$, indicating the high polarity of the analytes. Since adsoption of analytes on the adsorbent material (SWCNTs) is based on hydrophobic interaction, the sample $\mathrm{pH}$ is a significant factor in the enrichment of the analytes. As a result of the high adsorption of the all analytes in acidic solution maximum recovery was obtained at $\mathrm{pH} 3.0$ and it dropped clearly with the increase of $\mathrm{pH}$. Flow rate was another factor to increase the enrichment efficiency of analytes and control the extraction time that was adjusted by the manifold vacuum pressure to $150 \mathrm{ml} \mathrm{min}{ }^{-1}$ with SWCNTs as adsorbent. However, when double or triple layered disk was used, flow rate was decreased to around $50 \mathrm{~mL} \mathrm{~min}^{-1}$ similar to $\mathrm{C}_{18}$ and activated carbon. Zhou and co-workers [21] used multiwalled carbon nanotubes for pre-concentration of simazine and atrazine prior to HPLC-DAD. Under the optimal SPE procedure, the recoveries of two analytes were 86.2-103.7\%. However, Ru-Song et al. [22] used bamboo charcoal as SPE adsorbent in determination of atrazine and simazine in environmental water samples by HPLC-MS. Following optimization of enrichment conditions, among three different polarity solvents $(\mathrm{MeOH}, \mathrm{MeCN}$, acetone), $\mathrm{MeCN}$ had a high elution performance. To obtain proper sample solution $\mathrm{pH}$ for increasing the extraction efficiency of the analytes, different $\mathrm{pH}$ ranging from 3 to 11 was studied and the recoveries at $\mathrm{pH} 5-9$ were found to be appropriate. In optimization of flow rate of working solution for enhancement efficiency, flow rate $1.0-2.5 \mathrm{~mL} \mathrm{~min}{ }^{-1}$ was investigated and the flow rate of $2.5 \mathrm{~mL} \mathrm{~min}^{-1}$ was selected. Effect of sample volume on the recoveries was investigated in the range of 100-1000 mL. Quantitative recoveries were gained for sample volume up to $500 \mathrm{~mL}$, since using of this volume more than $500 \mathrm{~mL}$ for the target compounds was slightly declined the recoveries for simazine and atrazine and so a volume of $100 \mathrm{~mL}$ was selected. In this study, recoveries were ranged between $75.2 \%$ and $107.1 \%$ with RSD $8.3-8.7 \%$ better than previous study. Oasis HLB widely has been used as cartridge (water) by many authors either with hydrophilic or hydrophobic retention mechanisms. Both of these types of phase can be used for pesticides extraction from different matrices like honey [96], and water [97]. Acceptable outputs for all the mentioned compounds are gained using the method described by Delphine et al [96] in multiresidue analysis of trace pesticides and antibiotics in honey via HPLC-ESI-MS/MS. SPE method was applied by an oasis MCX cartridges (waters) with ion exchange combined with hydrophobic retention mechanisms under successfully conditions of $\mathrm{MeCN}$ - water (1:1), $37 \% \mathrm{HCl}$ before depositing honey solution at $\mathrm{pH}$ of 4 . Citric acid $0.2 \mathrm{M}$ was added into analytes before extraction to obtain the $\mathrm{pH}$ of around 4 with $20 \%$ ammunia. After washing the cartridge with deionised water and drying, compounds were eluted with $\mathrm{MeCN}, \mathrm{MeOH}, \mathrm{DCM}(50: 25: 25$, v/v). The results of different studies have revealed that the most broadly used eluents for desorption of pesticides and their degradation products from adsorbent materials are EtAc [14,92], MeOH [95], DCM [29], MeCN [97,100,104], aceton [6], or mixtures of these [96,99,105,106]. Most of the examples cited are multiresidue, including several groups of pesticides, and so mixtures of solvents are usually used to ensure high recoveries for all the target compounds. Different mixtures have been used, including EtAc-n-hexane [26,45], EtAc-MeOH-H2O [40], acetone-hexane [108], and EtAc-acetone [26]. $\mathrm{MeOH}$ was also used as SPE eluent by Wang et al. [109], who developed and validated a method for identification and quantification of trace levels of thirteen pesticides in apple-based infant food by LC-ESI-MS-MS. SPE is a successful method for extraction of pesticide residues in food samples but selection of proper adsorbent and elution solvent matched to phisycochemical characteristics of multiresidue analysis, small extracted sample volume by SPE adsorbents, high blank values are the problems that must be 
researched and removed. Table 4 reviews some SPE applications for determination of pesticides residues in food matrices and environmental samples.

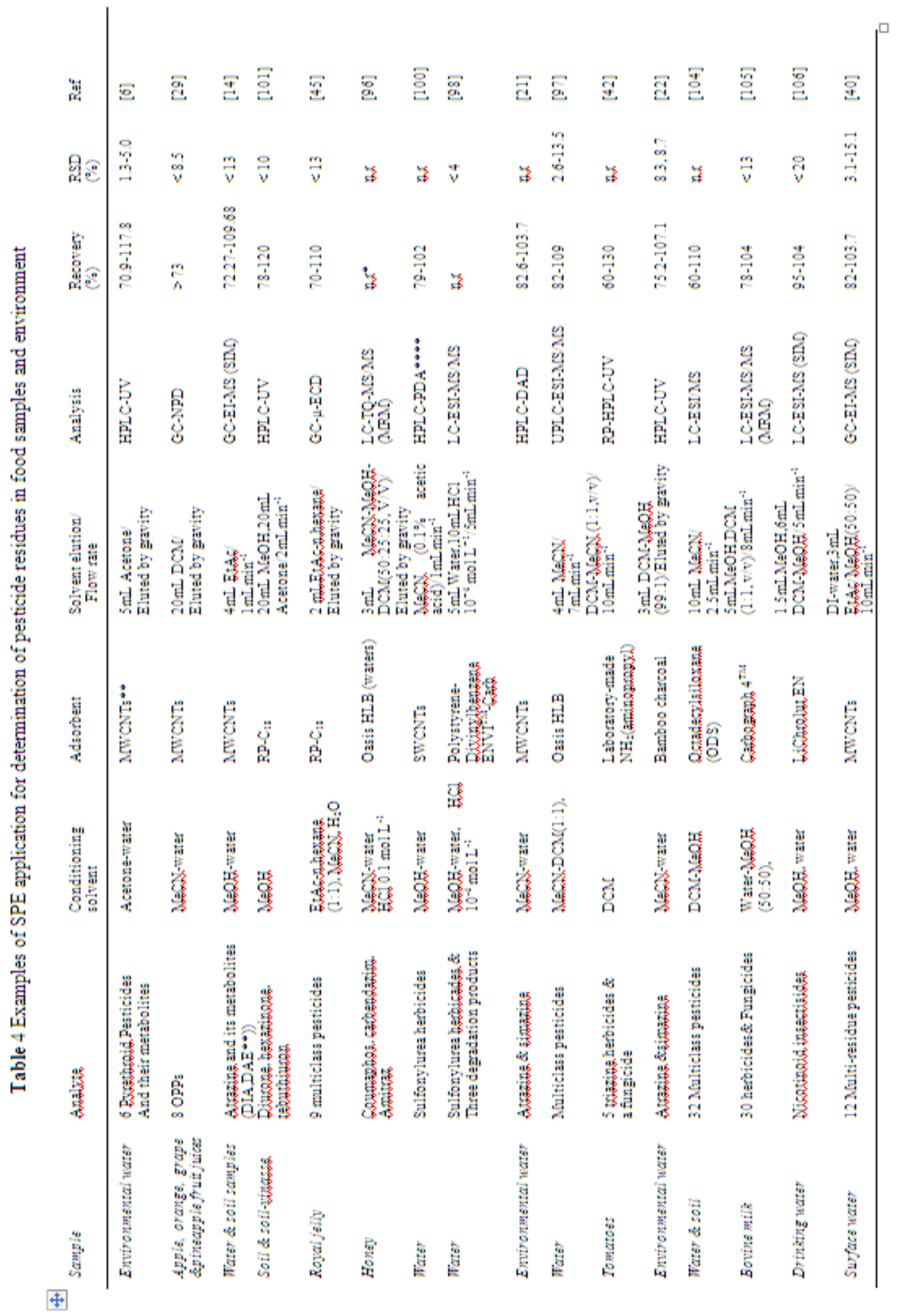


E. Sobhanzadeh et al. / Journal of Fundamental Sciences Vol 5, No 2 (2009) 106-128.

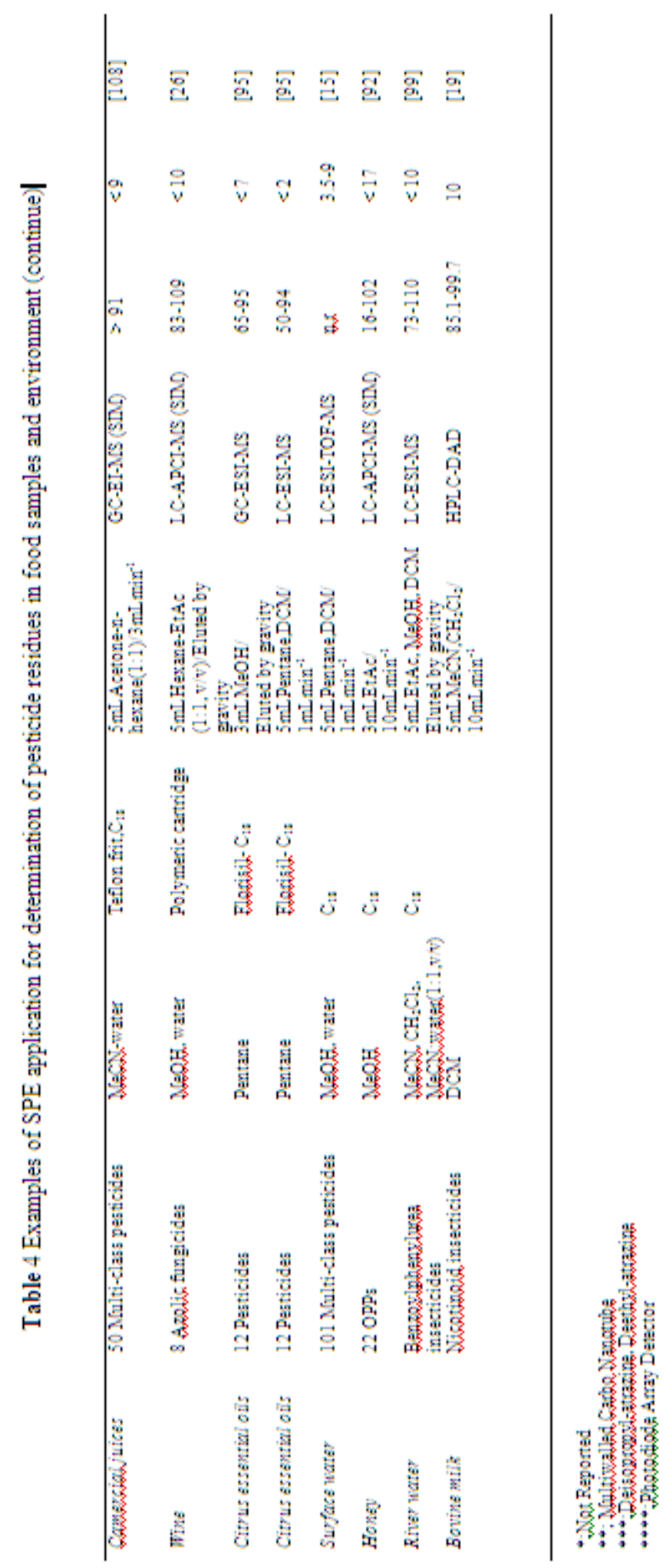




\subsubsection{Solid-Phase Microextraction (SPME)}

In solid-phase extraction, it is still necessary to extract the sample from the column, usually using of an organic solvent, before it can be injected into a separation method. This last step and the requirement of an organic solvent were eliminated in the ingenious SPME method, which was invented by Pawliszyn and co-workers [110,111]. They used a fiber coated with a stationary phase as the extraction medium. After carrying out an extraction from a sample solution, the fiber could be placed in the injection port of a gas chromatograph so the analytes were thermally desorbed directly into the carrier gas stream. A number of different fiber coatings are available, which offer a range of analyte solubilities and porosities, including the non-polar polydimethylsiloxane (PDMS), semi-polar PDMS-divinylbenzene (PDMS-DVB) and polar polyacrylate (PA) and Carbowax-divinylbenzene and the coated porous particle phase PDMS-Carboxen. Among these, PDMS fiber has been widely used in head-space (HS) extraction methods because it is the highest capacity fiber for polar compounds and enables successfully the collection of the different compounds from the sample. Recently SPME has been interfaced with HPLC and LC-MS to analysis of compounds that are nonvolatile and unstable heated. In this system an SPME-HPLC interface equipped with a specific desorption chamber is used before LC separation instead of thermal desorption in the injection port of the GC. Two types of fiber SPME techniques can be used to extract analytes: head-space (HS-SPME), and direct immersion (DI-SPME). In (HS)-SPME, the fiber is exposed in the vapour phase above a gaseous, liquid or solid sample. In (DI)-SPME, the fiber is directly immersed in clean liquid samples. Agitation of the sample is often performed with a small stirring bar to increase the rate of equilibration. In SPME, the amount extracted depends on the partition coefficient between the sample solution and the fiber. The main advantages of this method are that no solvent is required to elute the sample from the fiber and there is a direct transfer of analytes from the sample solution to the separation method. The fiber can be reused numerous times as the thermal elution step also cleans the fiber. The disadvantages are that the fiber is fragile even though it is shielded when it is out of the sample but it can be damaged by a build-up of involatile materials from the samples. Jingbin et al. [112] used polymethylphenylsiloxane-coated fiber for SPME-GC-ECD for determination of OCs and pyrethroid pesticides (non-polar pesticides) in vegetables with recoveries of 42.9 to $105.3 \%$. In this study, extraction efficiency of the synthesized hydroxyl-terminated polymethylphenylsiloxane (PMPS-OH) coated fiber $(70 \mu \mathrm{m})$ was compared with commercial fibers such as PDMS $(100 \mu \mathrm{m})$, PA $(85 \mu \mathrm{m})$ and PDMS/DVB $(65 \mu \mathrm{m})$. Since the mentioned pesticides are non-polar and low soluble in water, they contain one or more phenyl groups and so PMPS is one of the most common non-polar silicon oils with a chain structure. In comparison with PDMS, PMPS furnishes better thermal stability and its polarized phenyl has stronger л-л interaction with the phenyl group in aromatic compounds. The results showed that, the extraction efficiency of the PMPS coated fiber for selected pesticides with HS-SPME was higher than commercial fibers and DI-SPME mode. Among three commercial SPME fibers for the selected pesticides, PDMS $(100 \mu \mathrm{m})$ resulted the highest overall extraction efficiency and PA $(85 \mu \mathrm{m})$ showed the lowest extraction efficiency, while the efficiency of the PMPS-coated fiber was much better than of PDMS $(100 \mu \mathrm{m})$. HS-SPME is often used as a routine technique for the extraction of pesticides from liquid and solid samples. OPs and OCs are the most broadly compounds that have been investigated by this method because of their thermal stability and volatility. The extraction process of SPME method can be relatively slow because it relies on the sufficient stirring or diffusion to bring the analytes in to the location of the fiber. In addition, good reproducibility requires that equilibrium is established. A kind of SPME extraction is Single-drop microextraction (SDME) that is a solvent-minimized sample pretreatment procedure and also has been used to analyze carbamates and organophosphorus pesticides in water samples [113-114]. However, the disadvantages of SDME are as follows: fast stirring often break up the organic solvent drop, air bubble is easily forming [115], the extraction procedure is time-consuming and in most cases equilibrium is not easily attained even after a long time [23]. In order to eliminate these restrictions, hollow fiber membrane-protected LPME (HFM-LPME) [116-117] has been reported as an alternative. In this technique, the solvent is held and protected by an HFM. However, some drawbacks, such as memory effects caused by the on line configuration, and poor reproducibility because of manual cutting or/and sealing of the membrane in the laboratory have been reported [118]. Lingyan et al. [119], applied dispersive liquid-liquid microextraction (DLLME) as sample pretreatment method coupled with HPLC-FID for the analysis of triazophos and carbaryl pesticides in water and fruit juice samples. The extraction was performed under optimized conditions including, extraction solvent: tetrachloroethane $(15 \mu \mathrm{L})$, dispersive solvent: $\mathrm{MeCN}(10 \mathrm{~mL})$, without addition of salt in time of below 5 s. The obtained enrichment factors for carbaryl and triazophos were 87.3 and 275.6 respectively. In this technique a proper mixture of extraction and dispersive solvents is rapidly injected into an aqueous sample by a syringe, resulting in the formation of the cloudy solution. This technique (DLLME) has been employed in analysis of trace organic contaminants and metal ions in environmental liquid samples [120]. Lidia and co-workers [121] used a combination of DI-SPME with sample stacking micellar electrokinetic chromatography (MEKC) for analysis of 11 multiclass pesticide residues in red wine. SPME was performed by use of PDMS/DVB fibers and the large sample volumes were injected into the capillary by reversed-electrode polarity stacking mode (REPSM). Apparent recovery values with REPSM-MEKC-DAD were ranged 
between 90 and 107\%. The application of SPME-MS has not been considerably established in pesticide analysis. Theses combinations with GC-MS and LC-MS should be expected in the near future.

\subsubsection{Stir-Bar Sorptive Extraction (SBSE)}

The SPME fiber has a relatively small volume of bond stationary phase that often cause the extraction to be incomplete. Even with a favorable distribution coefficient, the phase ratio between the fiber and the sample solution are often unfavorable so that the partitioning can still leave a significant amount of the analyte in the sample phases. This problem prompted the development of the stir-bar extraction system, which uses a magnetic stir bar or a fiber coated with a bonded adsorbent layer such as a polymethyl diethyl siloxane. Alternatively, a magnetic stirring can be inserted into a short length of PDMS tubing. The surface area of the stirring bar is higher than a fiber and the volume of the adsorbent layer is much larger that can be a higher phase ratio than in SPME and hence higher extractions yields. The stir-bar is simply rotated in the sample, removed and extracted thermally for GC [24] or into a solvent for LC [122]. The sample is stirred typically for 30$240 \mathrm{~min}$ and the extraction time is controlled and determined by means of sample volume, stir bar dimensions and stirring speed. In order to optimize the extraction time, the analyte recovery must be measured as a function of the extraction time. The good recoveries are obtained under equilibrium conditions. When the extraction time increases, no additional recovery is observed. However, in SPME technique, selected sampling times are often shorter than the time needed to reach full equilibrium. The non-equilibrium conditions are gained in proper sensitivity and repeatability when the extraction time is not too long. Application of sorptive extraction with PDMS for sample preparation furnishes the considerable enrichment, no displacement effects, rapid thermal desorption at mild temperatures. This technique enables the absolute amount of an analyte in a sample to be determined. Bicchi et al. [123], studied analysis of nine pesticide resdues in heterogeneous matrices and determined the experimental recovery of these pesticides from pear pulp on the basis of their absolute amounts in the sample. In this study the amount of analyte present was evaluated in matrix and extraction of diluted samples was performed by the stir bar. The main difficulty of this method is that it is hard to automate the rinsing and the extraction processes as well as the removal of the stir-bar from the sample matrix. Liu et al. [124,125] used sol-gel technology in order to achieve thin layers of PDMS on stirring road. Bicchi and co-workers in another studuy [126] reported the use of a dual phase stir bar both in DI-SBSE mode and in HD-SBSE mode with PDMS coating and a carbon adsorbent material inside. This system caused the combination of both sorption and adsorption with high recovery of volatile compounds emitted from plant material. In liquid desorption technique the stir-bar is placed in a small vial and is desorbed by using non-polar solvent for GC analysis or with polar solvents for LC analysis. It should be noted that stir bar can be reused for 20-50 extractions. Leon et al. [127] described a multi-residue method for analysis of PCBs and PAHs and pesticides combined with GC-MS based on ISO/EN 17025. Thermal desorption procedure was carried out during $14 \mathrm{~h}$ by use of a $2 \mathrm{~cm}$ stir-bar coated with a $0.5 \mathrm{~mm}$ thick PDMS film followed by GC-MS in scan mode. LODs were 0.1-1.0 $\mathrm{ng} \mathrm{L}^{-1}$ and the obtained results were successfully close to the results obtained by classical method. In another paper a stir-bar sorptive extraction, followed by liquid desorption and large-volume injection capillary gas chromatography (SBSE-LD-LVI-GC-MS) was developed by Serodio and assistants [24] for analysis of pyrethroid pesticides in water samples. The extraction was performed using of stirs bar coated with $47 \mu \mathrm{L}$ PDMS under conditions of an equilibrium time of $60 \mathrm{~min}, 5 \% \mathrm{MeOH}$ as organic modifier and $\mathrm{MeCN}$ as back-extraction solvent. Good accuracy (81.8-105\%) and remarkable reproducibility $(<11.7 \%)$ with excellent recovery were obtained. SBSE is more sensitive and accurate than SPME but the main drawback of SBSE is the desorption step because analyte loaded on coated stir bars cannot be desorbed directly in the injection port of a GC and so the analyte must be back extracted into a appropriate solvent which causes an additional desorption step. SPME and SBSE were compared with each other by Blasco and coworkers [122] in analysis of pesticide residues from honey in combination of these methods with LC-MS. According to obtained results both techniques are simple, cheap and can be done with low consumption of solvents without any preliminary sample preparation step. Linearity and precision obtained by two methods were similar, while these results in SBSE were more accurate and sensitive than SPME. SBSE method is applied in analysis of halogenated solvents, volatile aromatics, PAHs, PCBs pesticides, odor compounds and organic compounds. Due to the apolar character of PDMS, it is not successful for the extraction of polar compounds except when they have been previously derivatised, hence SBSE has been applied commonly in extraction of non-polar and weakly polar compounds. Even in sample derivatisation of strong polar analytes to produce more hydrophobic species, this method is not suitable and extraction of them is difficult by PDMS-coated stir bars. Table 5 reviews some recent applications of SPME and SBSE methods in analysis of pesticide residues in different samples. 


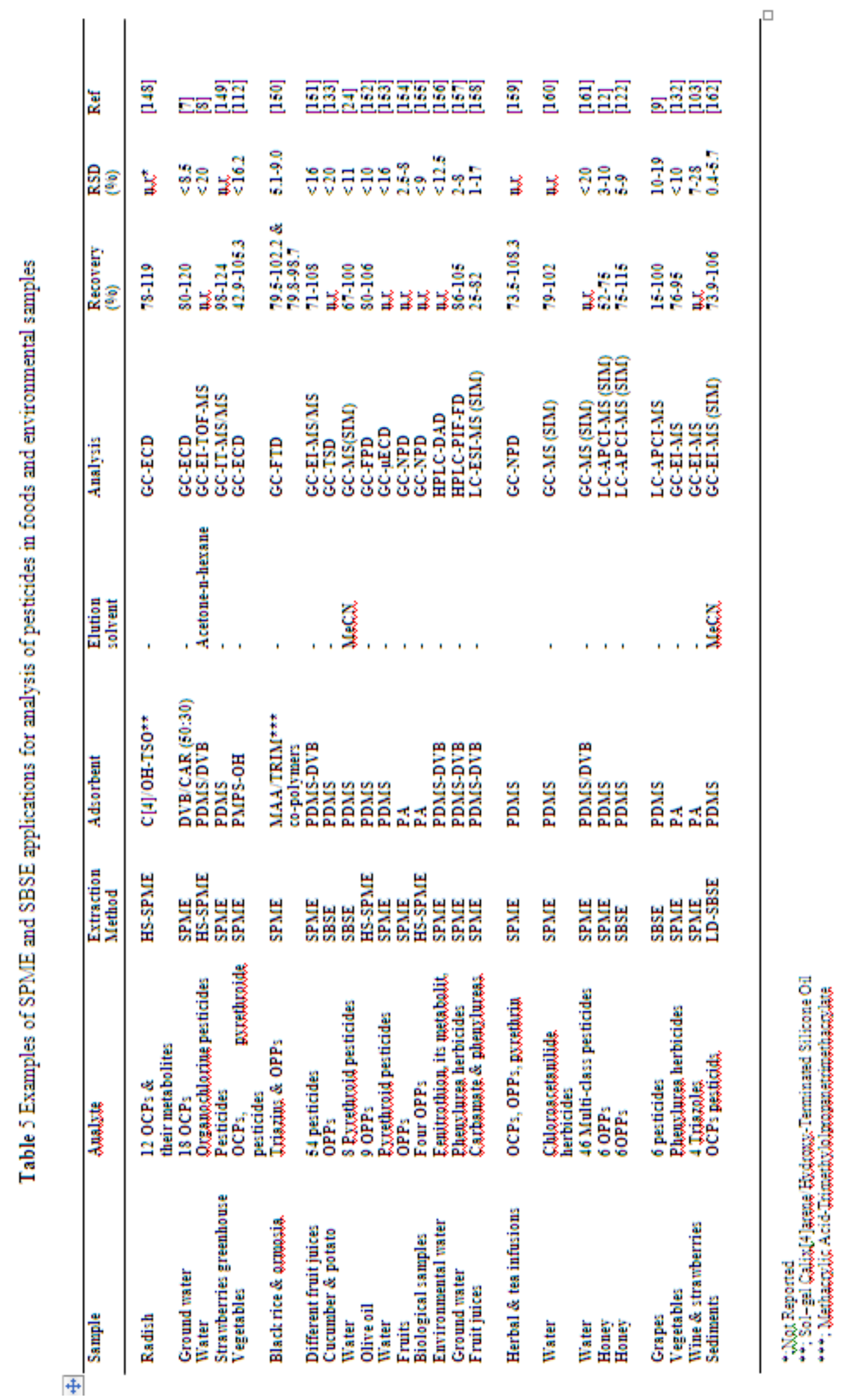




\section{CHROMATOGRAPH ANALYSIS}

In 1970s, replacement of traditional extraction such as liquid-liquid extraction (LLE) combined with high gas chromatography-mass spectrometry (GC-MS) with developed novel extraction methods, allowed investigation about the effects of trace pollutants such as chlorinated pesticides, petroleum hydrocarbons and polyaromatic hydrocarbons (PHAs) in the environment. A first step towards multi-residue method was based on thin layer chromatography (TLC), which employed on-plate detection often based on biological activity such as cholinesterase inhibition or fungi spores. [128]. Prevalence of capillary columns in GC measurements was demonstrated in a survey where over $90 \%$ of GC methods were designed with capillary columns. Although capillary columns are capable of refined separations, there are some limitations in the treatment of production methods and choise of materials. The multi-step method of column manufacture has intrinsic inefficiencies. The sol-gel method for column preparation can be considered as the most dramatic change in column technology in the past decade. Other developments such as the exploration of methods to stabilize coatings or to characterize extra thick films of stationary phases were introduced commercially in 2000. Polydimethylsiloxane or phenymethypolysiloxane are the most commonly used non-polar stationary phases in GC today, that were subjected to refinements with hops of improved thermal stability to $400^{\circ} \mathrm{C}$ and higher. [129]. Addition of silphenylene unit to form tetramethyl-p-silphenylenedimethyl-diphenylsiloxane, resulted in reduced column bleed and increased the maximum allowable operating temperature. [130]. Phenyl group enhances thermal stability, presumably through backbone stiffing. However, the elution temperatures of analytes were increased by $15-30^{\circ} \mathrm{C}$ against comparable polysiloxanes. Mass spectrometry was invented in 1886 when Goldstein, a german physicist discovered positive ions in a low pressure electrical discharge tube. Rapid-MS analytical column has been used in order to high speed LP-GC-IT-MS/MS analysis of multi-class pesticides [131] in this system 14\% cyanopropylphenyl and 86\% dimethylpolysiloxane (BP-10) has been used as mobile phase in analysis of phenylurea herbicides [132]. Splitless injection technique has been employed before separation GC due to its robustness although it has some restrictions such as reduction of sample capacity, (up $102 \mu \mathrm{L}$ ) and the lack of retention of non-volatile co-injected compounds in the liner subsequently influences sensitivity. It is also unable for matrices samples. The advent of programmed-temperature vaporization (PTV) injectors solved these analytical difficulties as these injectors can be employed using sample volumes up to $5 \mu \mathrm{L}$ without matrix effects. Matrix effects can be eliminated by releasing high-boiling co-extracted compounds through split vent or by trapping them on a liner. In this field Kirchner et al. [133] presented the use of PTV inlet in the cold splitless mode under optimized conditions because sample vaporization and sample transformation into the column can be done better with good repeatability in comparison with traditional splitless GC. Many pesticides are not amenable to be analyzed by GC as a result of their thermal instability and polarity. In the past 20 years, liquid chromatography has been applied in environmental field with very few samples. Today, the instrumental detection limits are below 0.1 picogram (pg). The techniques used for introduction and analysis of liquid samples by MS can be classified in two groups including those that introduce the sample into the ionic source of the spectrometer, namely the particle beam (PB), and those that allow 'soft ionization' of the sample, namely thermospray (TSP) or interfaces of atmospheric pressure ionization (API). API includes a group of interfaces, commonly called electrospray (ESP), ionspray (ISP), and atmospheric pressure chemical ionization (APCI). ESP is the softest ionization technique available for LC-MS and has permitted large labile molecules to be studied intact. High sensitivity and capability of analysis of thermally labile and highly polar compounds are two advantages of ESP in comparison with TSP. Sveltana et al. [134] demonstrated that APCI in negative ion mode has larger linearity range, lower detection limits and less sensitive to the differences in chemical structure of analytes and nature of applied solvents than negative ion ESI in analysis of dietary tocopherols. APCI is very sensitive in analysis of weakly basic compounds and pesticides such as triazines and phenylureas herbicides that can be simply protonated by gas-phase, mobile-phase ions, depending on their proton affinity. Thurman et al. [135], compared APCI and ESI for determination of multi-class pesticides by LC-MS. When APCI was used, sensitivity for neutral and basic pesticides was more than those when ESI was used. By contrast, ESI was more sensitive than APCI for cationic anionic herbicides. ISP interface was originally introduced by Bruins et al [136] to enhance the ion evaporation of the ESP. In the ISP interfaces, the electrospraying process is assisted by coaxial pneumatic nebulization of the LC column effluent. The main advantage of the ISP interface over the ESP is the tolerance of higher flow rate. Flow rates of 40-50 $\mu \mathrm{L}$ $\mathrm{min}^{-1}$, which are compatible with $1 \mathrm{~mm}$ inner diameter LC column, can be accommodated. The API process is a soft ionization method which typically generates only protonated molecular ions $[\mathrm{M}+\mathrm{H}]^{+}$in positive chemical ionization $(\mathrm{PCI})$ mode or deprotonated molecular ions $[\mathrm{M}-\mathrm{H}]^{-}$in negative chemical ionization $(\mathrm{NCI})$ mode, thus presents the molecular mass information which is considered the most important criterion for identification of the analyte. Structural information for identification purposes can be obtained by applying appropriate voltage difference on two regions the sample cone and the first skimmer of the API source. Today, LC-tandem MS has been widely used with very good sensitivity and selectivity in analysis of food and environmental pollutants. Yoshioka et al. [32] used atmospheric pressure photo-ionization (APPI) interface for LC-MS analysis of carbamate pesticides in fruit and vegetable to overcome the suppression difficulties encountered with APCI and ESI interfaces, but the use of APPI-MS-MS has not been reported in any literature. Chin et al. 
[137] demonstrated when APPI and APCI were used as source in LC-MS for analysis of phenylurea and carbamate pesticides, APPI and APCI showed lower background signals and fewer background peaks than ESI, and phenylureas gave better $\mathrm{S} / \mathrm{N}$ from APCI or APPI than from ESI. By contrast, the results illustrated that for carbamates the $\mathrm{S} / \mathrm{N}$ is better from ESI than from APCI or APPI. Some of these pesticides exhibited protonated and sodiated dimers in the full scan ESI spectra. Triple quadrupole (QqQs), ion trap (ITs), quadrupole time of flight (Qq-TOF) and recently Q-linear traps (LITs) has been commonly employed in LC-MS/MS. Q-TOF has been introduced with the analysis of biopolymers in mid [138]. The use of TOF instruments increased the accuracy $\mathrm{m} / \mathrm{z}$ measurements and resolution mass, which are usually within a few parts-per-million (ppm) of the extract $\mathrm{m} / \mathrm{z}$ values calculated from the nuclide masses and the ionic charge $\mathrm{z}$. However, in most of published literatures, quadrupole and ion-trap instruments have been used because they provide greater ease of operation, high robustness, and relatively low cost in comparison with TOF instruments. Garcia et al. [139] described a comprehensive method for analysis of 100 pesticides in food based on the combined use of LC-TOF-MS and LC-MS ${ }^{2}$ using QqLIT and compared three stages including: 1. automated pesticide screening by LC-TOF-MS; 2. identification by LCTOF-MS accurate-mass measurements; and 3. confirmation and quantitation by LC-MS ${ }^{2}$. In the first stage a set of data were obtained, including $\mathrm{m} / \mathrm{z}$ accurate-mass windows (within $20 \mathrm{mDa}$ width) and retention time in order to build the automated screening procedure, which was created automatically by assigning retention time and the $\mathrm{m} / \mathrm{z}$ mass window for each target pesticide. After analysis and identification by LC-TOF-MS and confirmation using two MRM transition, quantitation was carried out by LC-MS/MS using a QqLIT instrument (Figure 1). The obtained results were satisfactory. As for the reported literature by Amadeo et al. [140] there are no pitfalls in identification and quantitation in pesticide residues analysis by LCQqQ-MS-MS when the number of target compounds is around 100 or below. For a routine laboratory, it is very difficult to maintain a large number of methods, each with a limited number of target analytes (e.g. 300) for practical reasons and to get methods accredited. It should be noted that when LC-MS-MS techniques are employed, the scope and the capabilities of these MRMs are limited to a small number of target pesticide, hence pesticides which are not previously incorporated as targets analysis in the MRMs applied are not acquired and so not detected. Besides, as the number of target compounds in a single run increases, identification involves with some problems. So the main advantage of TOF-MS analysis for large-scale screening is the ability to test a data file for a theoretically unlimited number of pesticides. However, the applications of TOF for pesticide residues analysis are restricted in comparison with other MS techniques (e.g., QqQ-MS) due to its low efficiency while achieving reliable quantitative information. Soler and assistants [141] showed that the obtained results by use of LC-TQ-MS for quantitative analysis of pesticides in orange had higher precision, linearity and robustness in comparison with the results obtained from LC-QIT-MS. Nevertheless, both systems could be employed for qualitative and quantitative analysis of traditionally treated oranges. LC-MS (QqQ) have been applied in analysis of different classes of emerging contaminants in solid and aqueous environmental samples, using the multiple reaction monitoring mode (MRM) and obtaining LODs of typically ng $\mathrm{L}^{-1}[142]$. Among different used columns in LC for analysis of pesticides in food samples, reversed-phase octadesyl chromatography $\mathrm{C}_{18}$ columns $\left(4.6 \mathrm{~mm}\right.$ i.d.) and to a lesser extent octyl $\mathrm{C}_{8}$ have been commonly used. Hernando et al. [143] evaluated different LC-QLIT-MS (MRM) conditions to obtain sufficient sensitivity for the detection of pesticides in olive oil by using turboionspray source in positive mode. In this work, two different chromatographic columns $\left(\mathrm{C}_{18}, 100 \times 2.1 \mathrm{~mm}\right.$ i.d., $1.8 \mu \mathrm{m}$ and $\left.\mathrm{C}_{18}, 150 \times 4.6 \mathrm{~mm}, 5 \mu \mathrm{m}\right)$, different working flows $(200$ and $\left.600 \mu \mathrm{l} \mathrm{min}{ }^{-1}\right)$ and different injection volumes $(5$ and $10 \mu \mathrm{l})$ were studied. The mobile phases used in both columns were HPLC water, $0.1 \%$ formic acid as mobile phase $\mathrm{B}$, and $\mathrm{MeCN}$ as mobile phase A. One approach applied to improve sensitivity was the use of small particle size (e.g., $1.8 \mu \mathrm{m}$ ) columns, which can provide increased column efficiency with better baseline separation and narrower peaks than standard particle size columns (e.g., 3.5-5 $\mu \mathrm{m}$ ). On the other hand, the sensitivity achieved in small particle size columns is limited by the volume of sample that can be injected. In high-demand conditions, small particle size columns, such as $2.1 \times 100 \mathrm{~mm}$, could even support the injection of higher volumes (e.g., 10 $\mu \mathrm{L})$ than the maximum recommended $(5 \mu \mathrm{L})$ without significant changes in the column pressure. But the disadvantage this is a worsening of the peak shape. Another option to optimize sensitivity was flow rate that upon exploring two flow rates200 and $600 \mu \mathrm{L} / \mathrm{min}$ in term of sensitivity, a superior response was observed at $200 \mu 1 \mathrm{~min}^{-1}$, and so this was judged to be more suited to the trace determination of pesticides. The benefit of using higher flow rates is a reduction in analysis time, which is ideal for routine laboratory analysis. However, reduced sensitivity was observed at the higher flow rate explored, which could be associated with a dilution effect or a less stable spray.

Therefore, the use of $\mathrm{C}_{18}(4.6 \times 150 \mathrm{~mm} 5 \mu \mathrm{m})$, at flow rate of 200 and injected sample of $10 \mu 1$ in MRM mode resulted the best sensitivity with LODs $\leq 1 \mu \mathrm{g} \mathrm{kg}$ for 84 pesticides, $\leq 5 \mu \mathrm{g} \mathrm{kg}^{-1}$ for 12 and $\leq 10 \mu \mathrm{g} \mathrm{kg}^{-1}$ for 4 pesticides. In another study Barcelo et al. [144] reported the application of LIT combined with orbitrap analyzer for identification of pesticide molecular in surface water (Figure 2). In the first step, extracted ion chromatogram were constructed by using a mass filter of $3 \mathrm{ppm}$ for the extract molecular mass (Fig.2B). according to Fig 2D, the comparison of measured spectrum and calculated spectrum of molecular $[\mathrm{M}+\mathrm{H}]^{+}$illustrates adequate agreement of the isotopic pattern for the ${ }^{37} \mathrm{Cl}$ signal and the mass error between theoretical and measured masses of $0.3 \mathrm{ppm}$ for $[\mathrm{M}+\mathrm{H}]^{+}$. Confirmation and identification was performed by comparison between the data dependent $\mathrm{MS}^{2}$ spectra of the compound and $\mathrm{MS}^{2}$ spectra predicted by 
Massfrontier software. Fig. 2E shows the predicting fragments matched molecular with three measured product ions. To prevent matrix interferences effects, the standard additional method, labeled internal standards, and external calibration plots have been recommended. The use of matrix-matched method is suggested for multi-residues analysis because of the lack of labeled standards for all analytes.

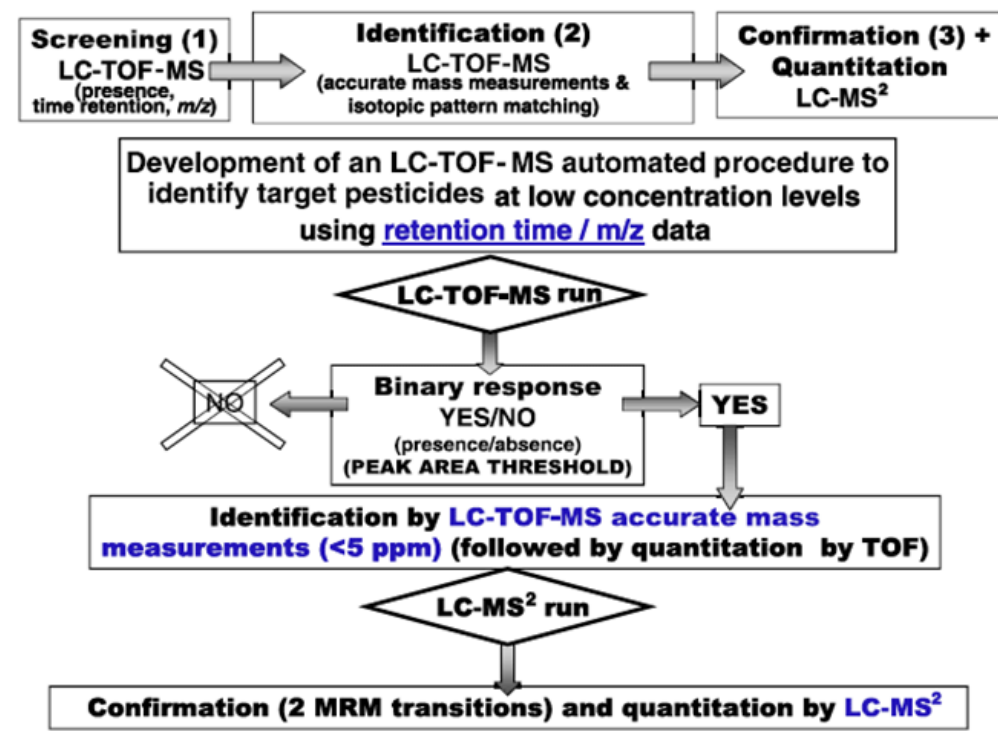

Fig. 1 Example of the combined use of LC-TOF-MS and LC-MS2 for large-scale screening of pesticides in food stuffs (for details, [139]). Theproposed workflow for screening, identification, confirmation and quantitation of target pesticides in vegetable samples comprised three steps:

(1) screening by LC-TOF-MS with retention-time / accurate-mass $\mathrm{m} / \mathrm{z}$ windows;

(2) identification via accurate-mass measurements ( $<5 \mathrm{ppm}$ error); and,

(3) confirmation (2 MRM transitions) and quantitation by LC-MS2. (Reprinted with permission from Ref. [139])
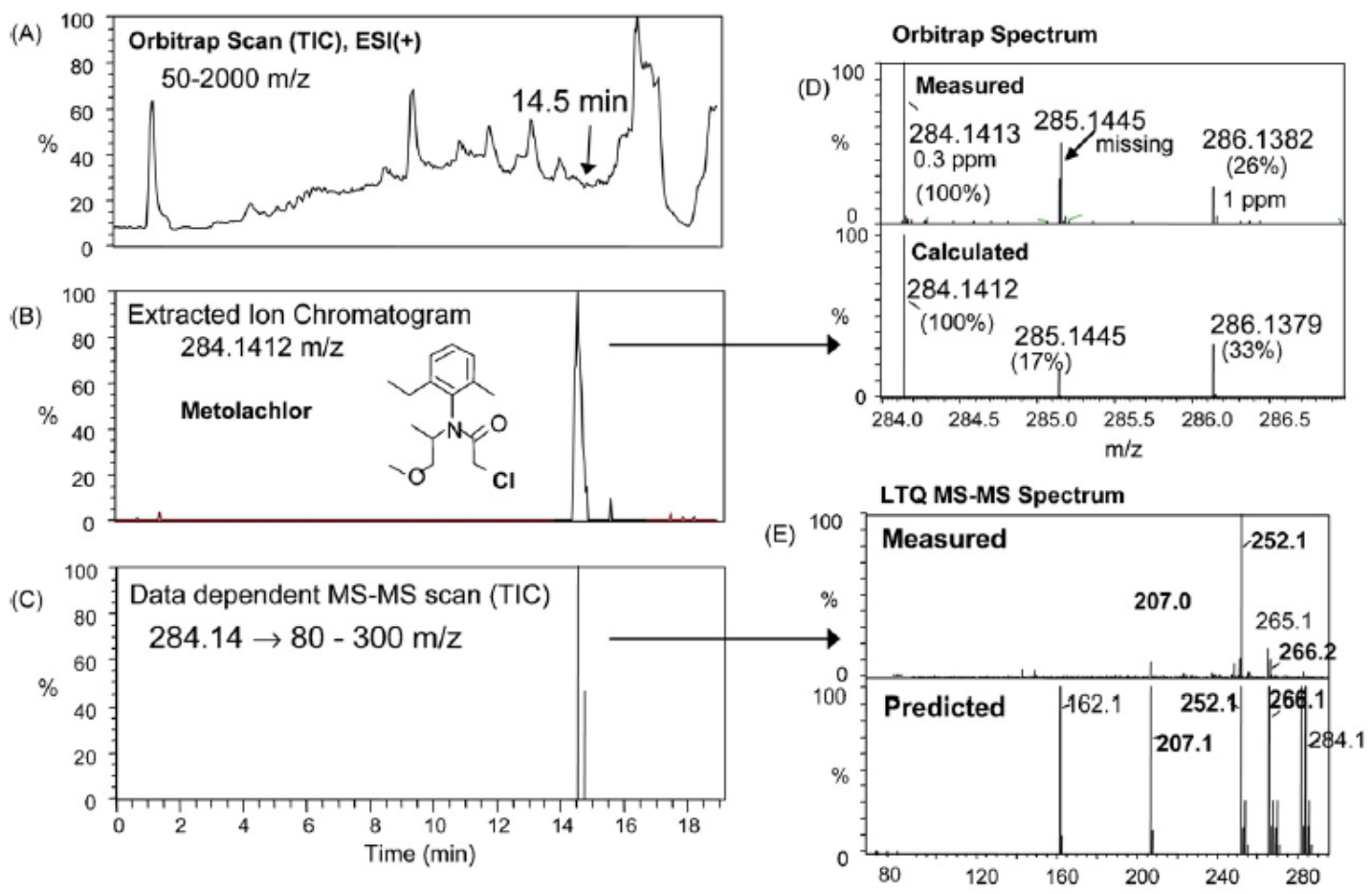

Fig. 2 Identification of metolachlor in a lake water sample using a linear ion trap combined with an orbitrap analyzer. (Reprinted with permission from Ref. [144]) 


\section{CONCLUSION}

Since, the pesticides belong to different groups of chemical substances with a broad range of polarity and acidic characteristics, so analysis of pesticide residues makes special problems for the scientists. Analysis of these compounds involves different steps, such as extraction, clean up or interference removal, determination of pesticide residues and confirmation of their identity by using different techniques. Ideally, residue isolation should involve as few steps as possible which require minimal expendable materials and low cost and also contains the ability to be automated with high removal interferences. In order to analyze the pesticide residues in a variety of samples, a proper method is selected based on cost, selectivity and sensitivity depend on the types of compounds that need variant instrumental optimization methods specifically the polar compounds that are unstable heated. New sample extraction and concentration methods are evolving towards automation to allow on-line extraction and analysis should increase the robustness as well as decrease the time for an analytical method. Among the extraction methods mentioned, solid-phase extraction is commonly used with often clean up step to remove interferences. In order to obtaining sensitive and selective analysis, the use of LC system is preferred rather than GC as the most of target analytes are polar, non-volatile and unstable heated. The main advantage of application of LC-MS/MS is the simplification of extraction methods. Between different LC techniques, LC-ESI-MS ${ }^{2}$ provides credible results at levels of subnanogram per liter or per gram and so it can be a selective method for this aim. In spite of the high sensitivity and selectivity of LC-MS-based methods, we require knowing more about the significance of the matrices effects in analysis of pesticide residues in food samples like vegetables and fruits.

\section{REFERENCES}

[1] Lesueur, C., P. Knittl, M. Gartner, A. Mentler and M. Fuerhacker, 2008. Intl. J. Food Control. , 19: 906-914.

[2] Soler, C., J. Manes and Y. Pico, 2006. Intl. J. Chromatogr A., 1109: 228-241.

[3] Papadakis, E.N., Z. Vryzas and E. Papadopoulou-Mourkidou, 2006. Intl. J. Chromatography A., 27: 6-11.

[4] Jianfeng, S., L. Guyuan, L. Wenhao, Zh. Jinhu and C. Donghua, 2008. Intl. J. Science of Journal Chromatography., 26: 292-300.

[5] Aguilera, A., M. Brotons, M. Rodriguez and A. Valverd, 2003. Intl. J. Agric Food Chem., 51(19): 5616-5621.

[6] Zhou, Q., J. Xiao, W. Wang, G. Liu,Qizeng Shi and J. Wang, 2006. Intl. J. Talanta., 68: 1309-1315.

[7] Raposo J'unior, JL. and N. R'e-Poppi, 2007. Intl. J. Talanta., 72: 1833-1841.

[8] C. Mmualefe, L., N. Torto, P. Huntsman-Mapila and B. Mbongwe, 2009. Intl. J. microchemical., 91: 239-244.

[9] Juan-García, A., J. Mañes, G. Font and Y. Picó, 2004. Intl. J. Chromatography A., 1050: 119-127.

[10] Tadeo, J.L., C. Sanchez- Brunete, R.A. Perez and M.D. Femandez, 2000. Intl. J. Chromatography A., 882: 175191.

[11] Pico, y., G. Font, J.C. Molto and J. Manes, 2000. Intl. J. Chromatogr A., 882: 153-173.

[12] Blasco, C., G. Font and Y. Pico, 2005, Intl. J. Chromatogr A., 1098: 37-43.

[13] Tanaka, T., T. Hori, T. Asada, K. Oikawa and K. Kawata, 2007. Intl. J. Chromatography A., 1175: 181-186.

[14] Min, G., S. Wang, H. Zhu, G. Fang and Yan Zhang, 2008. Intl. J. Science of the Total Environment., 396: 79-85.

[15] Ferrer, I. and E. Michael Thurman, 2007. Intl. J. Chromatography A., 1175: 24-37.

[16] Rissato, S.R., M.S. Galhiane, F.R.N. Knoll and M.B. Apon, 2004. Intl. J. Chromatography A., 1048: 153-159.

[17] Coscolla,C., V. Yusia, P. Marti and A. Pastor, 2008. Intl. J. Chromatography A., 1200: 100-107.

[18] Hercigova, A., M. Domotorova, E. Matisova, M. Kirchner, R. Otrekal and V. Stefuca, 2005. Intl. J. Chromatography A., 108: $446-453$.

[19] Garcia de Llasera, Martha P./ Reyes-Reyes and L. Maria, 2009. Intl. J. Food Chemistry., 114: 1510-1516.

[20] E. G. Amvrazi and T. A. Albanis, 2008. Intl. J. Agric. Food Chem., 56: 5700-5709.

[21] Zhou, Q., J. Xiao, W. Wang, G. Liu,Qizeng Shi and J. Wang, 2006. Intl. J. Talanta., 68: 1309-1315.

[22] Zhao, R., J. Yuan, T.Jiang, J. Shi and C. Cheng, 2008. Intl. J. Talanta., 76: 956-959.

[23] Chen, L., L. Ding, D. Song, H. Zhang, J. Li, K. Zhang, Y. Wang and H. Zhang, 2007. Intl. J. Analaytacal Chimica Acta., 589: $239-246$.

[24] Sero`dio, P. and J. M.F. Nogueira, 2005. Intl. J. Anal Bioanal Chem., 382: 1141-1151.

[25] [25] Sergi, M., A. Gentili, D. Perret, S. Marchese, S. Materazzi and R. Curini, 2007. Intl. J. Chromatographia., 65: 757-761.

[26] Nozal, Ma.J., J.L. Bernal, J.J. Jim'enez, Ma.T. Mart'in and J. Bernal, 2005. Intl. J. Chromatography A., 1076: 90-96.

[27] you, J., H. Zhang, H. Zhang, A. Yu, Tingting Xiao, Y. Wang and D. Song, 2007. Intl. J. Chromatography B, 856: 278-284.

[28] S'anchez-Brunete, C., E. Miguel and J.L. Tadeo, 2008. Intl. J. Talanta., 74: 1211-1217.

[29] Ravelo-Perez, L.M., J. Hernandez-Borges and M. Angel Rodriguez-Delgado, Intl. J. Chromatography A., 1211 (2008) 33-42

[30] Fujita, H., K. Honda, N. Hamada, G. Yasunaga and Y. Fujise, 2009. Intl. J. Chromospheraphy., 74: 1069-1078.

[31] Cheng, J., M. Liua, Y. Yu, Xiupin Wang, H. Zhang, L. Ding and H. Jin, 2008. Intl. J. Meat Science., Corrected Proof.

[32] Yoshioka, N. , Y. Akiyama and K. Teranishi, 2004. ntl. J. Chromatography A., 1022: 145-150.

[33] Roos, A.H., A.J.V Munsteren, F.M. Nab and L.G.M. Th. Tuinstra, 1987. Intl. J. Anal Chim Acta., 196: 95-102

[34] Holstege, D.M. , D..L Scharberg, E.R. Tor, L.C. Hart, F.D. Galey, 1994. Intl. J. AOAC., 77: 1263-1274.

[35] Cheng, J., M. Liu, X. Zhang, L. Ding, Y. Yu, X. Wang, H. Jin and H. Zhang, 2007. Intl. J. Analytica Chimica Acta., 590: 34-39.

[36] Pirard, C. , J. Widart, B.K. Nguyen, C. Deleuze, L. Heudt, E. HaubrugeE. De Pauw, J.F. Focant, 2007. Intl. J. Chromatography A., 1152: 116-123.

[37] Geov^ania, M., D. Silva, A. Aquino, H. Silveira Do'rea and S. Navickiene, 2008. Intl. J. Talanta., 76: 680-684.

[38] Fuentes, E., M. E Baez and R. Labar, 2007. Intl. J. Chromatography A., 1169: 40-46.

[39] Iglesias-Garcia, I. , M. Barriada Pereira, M.J. Gonzalez-Castro, S. Muniategui-Lorenzo, P. Lopez-Mahia and D. Prada-Rodriguez, 2008. Intl. J. Anal Bioanal Chem., 391: 745-752.

[40] Wang, S., P. Zhao, G. Min and G. Fang, 2007. Intl. J. Chromatography A., 1165: 166-171.

[41] Smalling, K.L. and K.M. Kuivila, 2008. Intl. J. Chromatography A., 1210: 8-18.

[42] Melo, L.F.C., Carol H. Collins and I.C.S.F. Jardim, 2005. Intl. J. Chromatography A., 1073: 75-81. 
[43] Garc1'a-Reyes, J.F., C. Ferrer, M. Jose' Go'mez-Ramos, A. Molina-D1'az and A.R. Ferna'ndez-Alba, 2007. Intl. J. Anal Chem., 26 (3).

[44] García-Reyes, J.F., C. Ferrer, E.M. Thurman, A.R. Fernández-Alba and I. Ferrer, 2006. Intl. J. Agric Food Chem., 54: 6493-6500.

[45] Karazafiris, E., U. Menkissoglu-Spiroudi and A. Thrasyvoulou, 2008. J. Chromatography A., 1209: 17-21.

[46] Goto, T., Y. Ito, S. Yamada, H. Matsumoto, H. Oka and H. Nagase, 2006. Intl. J. Anal Chim Acta., 555: 225-232.

[47] Hernández-Borges, J., J. Cabrera Cabrera, M. Ángel Rodríguez-Delgado, E. M. Hernández-Suárez and J. Víctor Galán Saúco, 2009. Intl. J. Food Chemistry., 113: 313-319.

[48] Mezcua, M., C. Ferrer, J.F. García-Reyes, M. Jesús MartínezBueno, M. Sigrist and A.R. Fernández-Alba, 2009. Intl. J. Food Chemistry., 112: $221-225$.

[49] Kmellár, B. , P. Fodor, L. Pareja, C. Ferrer, M.A. Martínez-Uroz, A. Valverde and A.R. Fernandez-Alba, 2008. Intl. J. Chromatography A., 1215: $37-50$.

[50] Dong Nguyen, T., J. Eun Yu, D. Myung Lee and G. -Ho Lee, 2008. Intl. J. Food Chemistry., 110: 207-213.

[51] Lehotay, S.J., K. Mastovska and A.R. Lightfield, 2005. Intl. J. AOAC., 88: 615-629.

[52] Lehotay, S.J., K. Mastovska, S.J. Yun, 2005. Intl. J. AOAC., 88: 630-638.

[53] Leandro, C.C, R.J Fussell, B.J Keely, 2005. Intl. J. Chromatography A., 1085: 207-212.

[54] Díez, C., W.A. Traag, P. Zommer and P. Marinero and Atienza, 2006. Intl. J. Chromatography A., 1131: 11-23.

[55] Ferrer, I., J.F. García-Reyes, M. Mezcua, E.M. Thurman and A.R. Fernández-Alba, 2005. Intl. J. Chromatography A., 1082: 81-90.

[56] Garrido Frenich, A., P. Plaza-Bolanos and J.L. Martínez Vidal, 2008. Intl. J. Chromatography A., 1203: 229-238.

[57] Banerjee, K., D.P. Oulkar, S. Dasgupta, S.B. Patil, S.H. Patil, R.Savant and P.G. Adsule, 2007. Intl. J. Chromatography A., 1173: $98-109$.

[58] Shuling,S., Ma. Xiaodong and Li. Chongjiu, 2007. Intl. J. Food Control., 18: 448-453.

[59] Chen, S., X. Yu, X. He, D. Xie, Y. Fan and J. Peng, 2009. Intl. J. Food Chemistry., 113: 1297-1300

[60] Shim, J.H. , M.H. Lee, M.R. Kim, C.J. Lee and I.S. Kim, 2003. Intl. J. Biosci, Biotechnol, Biochem., 67(6): 1342-1348.

[61] Aguilera, A., M. Rodriguez, M. Botons, M. Boulaid and A. Valverd, 2005. Intl. J. Agric Food Chem., 53: 9374-9382.

[62] Rodil, R., A.M. Carro, R.A. Lorenzo and R. Cela, 2007. Intl. J. Chemosphere., 67: 1453-1462.

[63] J.W. King, Am. Lab. 30 (1998) 46.

[64] Von Holst, C., F. Serano, S. Sporring, E. Bjorklund and A. Muller, 2005. Intl. J. Chromatographia., 61: 391-396.

[65] Morales-Munoz, S., J. L. Luque and M. D. Luque de Castro, 2002. ntl. J. Chromatography A., 978: 49.

[66] Kania-Korwel, I., H. Zhao, K. Norstrom, X. Li, K. C. Hornbuckle and H. J. Lehmler, 2008. Intl. J. Chromatography A., 1214: 37-46.

[67] Hovander, L., L. Linderholm, M. Athanasiadu, A. Bignert, B. Fangstrom, A. Kocan, 2006. Intl. J. Environ. Sci. Technol., 40(12): $3696-703$.

[68] Jensen, S., L. Haggberg, H. Jorundsdottir and G. Odham, 2003. Intl. J. Agric Food Chem., 51: 5607.

[69] Gomez-Ariza, J. L., M. Bujalance, I. Giraldez, A. Velasco, E. Morales, 2002. Intl. J. Chromatography A., 946: 209-219.

[70] Andreu, V., Y. Pico', 2004. Intl. J. Anal. Chem., 23: 772-789.

[71] Sanchez, C., M. Ericsson, H. Carlson, A. Colmsjo, E. Dyremark, 2002. Intl. J. Chromatography A., 957: 227-234.

[72] Pẽna, A., F. Ruano, M.D. Mingorance, 2006. Intl. J. Anal Bioanal Chem., 385: 918-925.

[73] Ericsson, M. and A. Colmsjo, 2000. Intl. J. Chromatography A., 877: 141-151.

[74] Sanusi, A. , V. Guillet and MJ. Montury, 2004. Intl. J. Chromatography A., 1046: 35-40.

[75] Pateiro-Moure, M., E. Martinez-Carballo, M. Arias-Estevez, and J. Simal-Gandara, 2008. Intl. J. Chromatography A., 1196-1197: 110-116.

[76] Fuentes, E., M. E Baez and A. Quinones, 2008. Intl. J. Chromatography A., 1207: 38-45.

[77] Anastassiades, M., S.J Lehotay, D. Štajnbaher and F.J Schenk, 2003. Intl. J. AOAC Int, 86: 412-431.

[78] Leandro, CC., P.Hancock, RJ. Fussell and BJ. Keely, 2006. Intl. J. Chromatography A., 1103: 94-101.

[79] Barker, S.A., A.R. Long and C.R. Short, 1989. Intl. J. Chromatography A., 475: 353-61.

[80] Santana dos Santos, T. F., A. driano Aquino, H. Silveira Dórea and S. Navickiene, 2008. Intl. J. Anal Bioanal Chem., 390: 1425-1430.

[81] Abhilash, P.C., S. Jamil and N. Singh, 2007. Intl. J. Chromatography A., 1176: 43-47.

[82] Zhu, X., X. Qi, J. Wang, J. Yue, Z. Sun and W. Lei, 2007. Intl. J. Chromatographia., 65: 625-628.

[83] Hercegova, A., M. Domotorova, D. Kruzlicova and E. Matisova, 2006. Intl. J. Sep Sci., 29: 1102-1109.

[84] Wang, S., Y. Xu, C. Pan, S. Jiang and F. Liu, 2007. Intl. J. Anal Bioanal Chem., 387: 673-685.

[85] Radišic, M., S. Grujic, T. Vasiljevic and M. Lauševic, 2009. Intl. J. Food Chemistry., 113: 712-719.

[86] Chu, X-G., X-Z Hu and H-Y Yao, 2005. Intl. J. Chromatography A., 1063: 201-210.

[87] Bogialli, S., R. Curini, A. Di Corcia, M. Nazzari and D. Tamburro, 2004. Intl. J. Agric Food Chem., 52: 665-671.

[88] Bogialli S, G. D’Ascenzo, A. Di Corcia, G. Innocenti, A. Laganá and Pacchiarotta, 2007. Intl. J. Rapid Communications in Mass Spectrometry., 21: $2833-2842$.

[89] García-Reyes J.F, C. Ferrer, MJ. Gómez-Ramos, A. Molina-Díaz and AR. Fenández-Alba, 2007. Intl. J. Anal Chem., $26: 239-251$.

[90] Ferrer, C., M. J. Gómez, J. F. García-Reyes, I. Ferrer, E. M. Thurman and A. R. Fernández-Alba 2005. Intl. J Chromatography A., 1069:183-194

[91] Cunha S. C., J. O. Fernandes and Oliveira M. B. P. P, 2007. Food Addit Contam 24:156-164

[92] Fernandez, M., Y. Pico and J. Maries, 2002. Intl. J. Chromatographia., 56: 577-583.

[93] Blasco, C., M. Fernández, A. Pena, C. Lino, MI. Silveira, G. Font and Y. Pico, 2003. Intl. J Agric Food Chem., 51:8132-8138.

[94] -Muñoz, S., J. L. Luque-García and M. D. Luque de Castro, 2006. Intl. J. Anal Chim Acta., 557: 278-286.

[95] Barrek, S., O. Paisse and M. F. Grenier-Loustatol, 2003. Intl. J. Anal Bioanal Chem, 376: 157-161.

[96] Debayle, D., G. Dessalces and M. F. Grenier-Loustatol, 2008. Intl. J. Anal Bioanal Chem., 391: 1011-1020.

[97] Gervais, G., S. Brosillon, A. Laplanchea and C. Helen, 2008. Intl. J. Chromatography A., 1202: 163-172.

[98] Perreau, F., P. Bados, L. Kerhoas, S. Nelieu and J. Einhorn, 2007. Intl. J. Anal Bioanal Chem., 388: 1265-1273.

[99] Martinez, D. B., M. M. Galera, P. P. Vazquez and M. D. Gil Garcia, 2007. Intl. J. Chromatographia., 66: 533-538.

[100] Niu, H., Y. Shi, Y. Cai, F. Wei and G. Jiang, 2009. Intl. J. Microchim Acta., 164:431-438

[101] Lourencetti, C., M. R. Rodrigues Di Marchi and M. L. Ribeiro, 2008. Intl. J. Tlanta., 77: 701-709.

[102] Blasco, C., G. Font and Y. Pico, 2004. Intl. J. Cromatography A., 1028: 267-276.

[103] Asperger, A. , J. Efer, T. Koal, W. Engewald, 2002. Intl. J. Chromatography A., 960: 109-119.

[104] Vega, A.B., A.G. Frenich, J.LM. Vidal, 2005. Intl. J. Anal Chem Acta., 538: 117-127.

[105] bogialli, S., R. Curini, A. DI Corcia, A. Lagana, Intl. J. Chromatography A., 1102: 1-10.

[106] Seccia, S., P. Fidente, D. A. Barbini and P. Morrica, 2005. Intl. J. Analytica Chimica Acta., 553: 21-26.

[107] Furusawa, N., 2004. Intl. J. Anal Bioanal Chem., 378: 2004-2007.

[108] Albero, B., C. S'anchez-Brunete and J. L. Tadeo, 2005. Intl. J. Talanta., 66: 917-924

[109] Wang, J., W. Cheung and D. Grant, 2005. Intl. J Agric Food Chem., 53: 528- 537. 
[110] Lord, H. and J. Pawliszyn, 2000. Intl. J. Chromatography A., 885: 153-193.

[111] Zhang, Z., M.J. Yang and J. Pawliszyn, 1994. Int. J. Anal Chem., 66: 844-853.

[112] Zeng, J., J. Chen, Z. Lin, W. Chen, X. Chen and X. Wang, 2008. Intl. J. Analytica Chimia Acta., 619: 59-66.

[113] Xiao, Q., B. Hu, C. Yu and L. Xia, Z. Jiang, 2006. Intl. J. Talanta, 69: 848.

[114] Basheera, C., A.A. Alnedharyb, B.S. Madhava Raob and K.K. Leea, 2007. J. Anal. Chim. Acta, 605: 147.

[115] Shen, G. and H.K. Lee, 2002. Intl. J. Anal. Chem., 74: 648-654.

[116] Xiong, J. and B. Hu, 2008. Intl. J. Chromatography A., 1193: 7-18.

[117] Zhang, J. and H.K. Lee, 2006. Intl. J. Chromatography A., 1117: 31-37.

[118] Pedersen-Bjergaard, S. and K.E. Rasmussen, 2004. Intl. J. Anal. Chem., 23: 1-10.

[119] Fua, L., X. Liu, J. Hu, X. Zhao, H. Wangc and X. Wang, 2009. Intl. J. Analytica Chimica Acta., 632: $289-295$.

[120] Rezaee, M. , Y. Assadi, M.R. Milani Hosseini, E. Aghaee, F. Ahmadi and S. Berijani, 2006 Intl. J. Chromatography A., 1116: 1-9.

[121] Ravelo-Pérez, L. M., J. Hernández-Borges, T. M. Borges-Miquel and M. A. Rodríguez-Delgado, 2008. Intl. J. Food Chemistry, 111: 764-770.

[122] Blasco, C., M. Fernández, Y. Picó and G. Font, 2004. Intl. J. Chromatography A., 1030: 77-85.

[123] Bicchi, C., C. Cordero, P. Rubiolo and P. Sandra, 2003. Intl. J. European Food Res Technol., 216: 449-456.

[124] Liu, W.M. , H. Wang and Y. Guan, 2004. Intl. J. Chromatography A., 1045: 15-22.

[125] Liu, W.M. , Y. Hu, J. Zhao, Y. Xu and Y. Guan, 2005. J. Chromatography A., 1095: 1-7.

[126] Bicchi, C. , C. Cordero, E. Liberto, P. Rubiolo, B. Sgorbini, F. David and P.Sandra, 2005. Intl. J. Chromatography A., 1094: 9-16.

[127] Leon, V.M., J. Llorca-Porcel, B. Alvarez, M.A. Cobollo, S. Munoz, I. Valor, 2006. Intl. J. Anal. Chim Acta., 558: 261-266.

[128] Yung, S.S., A.I. Goldsmith and I. Smettena, 1996. Intl. J. Chromatogr A, 754: 3-16.

[129] Elceman, G.A., J.G. Torresday, E. Overton, K. Carney, F. Dorman, 2004. Intl. J. Anal Chem, 76: 3387-3394.

[130] Mayer, B.X., H. Kahlig and W. Rauter, 2003. Intl. J. Chromatography A., 993: 59-70.

[131] Arrebola, F.J., J.L. Martínez Vidal, M.J. González-Rodríguez, A. Garrido-Frenich and N. Sánchez Morito, 2003. Intl. J. Chromatography A., 1005: $131-141$.

[132] Berrada, H., G. Font, J. C. and Moltó, 2004. Intl. J. Chromatography A., 1042: 9-14.

[133] Kirchner, M., E. Matisová, R. Otrekal, A. Hercegová and J. de Zeeuw, 2005. Intl. J. Chromatography A., 1084: 63-70.

[134] Lanina, S. A., P. Toledo, S. Sampels, A. Kamal-Eldin and J. A. Jastrebova, 2007. Intl. J. Chromatography A., 1157: $159-170$.

[135] Thurman, E. M., I. Ferrer and D. Barcelo, 2001. Intl. J. Anal Chem., 73 (22): 5441-49

[136] Bruins, A.P., T.R. Covey and J.D. Henion, 1987. J. Anal Chem., 59: 2642-2650

[137] Meng, C. K., Agilent Technologies Inc, Environmental and Food

[138] Van Bocxlaer, J. F., S. R. Vande Casteele, C. J. Van Poucke and C. H. Van Peteghem, 2005 Intl. J. Analytica Chimica Acta., 529: 65-73.

[139] Garcia-Reyes, J.F., M.D. Hernando, C. Ferrer, A. Molina-D'1az,A.R. Intl. J. Anal Chem., 79: 7308-7323.

[140] Ferna'ndez-Alba, A. R. and J. F. Garci'a-Reyes, 2008. J. Anal Chem., 27: No. 11.

[141] Soler, C. , B. Hamilton, A. Furey, K.J. James, J. Mañes and Y. Picó, 2006, Intl. J. Anal Chim Acta., 571: 1-11.

[142] Rodriguez-Mozaz, S. and M.J. Lopez de Alda, D. Barcelo, 2004. Intl. J. Anal Chem.,76 (23) 6998-7006.

[143] Hernando, M.D., C. Ferrer, M. Ulaszewska, J.F. García-Reyes, A. Molina-Díaz and A.R. Fenández-Alba, 2007. Intl. J. Anal Bioanal Chem., 389: $1815-1831$.

[144] D. Barceló, D. and M. Petrovic, 2007. J. Anal Chem., 26:2.

[145] Westbom, R., A. Hussen, N. Megersa, N. Retta and L. Mathiasson, 2008. Intl. J. Chemospher., 72: 1181-1187.

[146] Albero, B., C. Sánchez-Brunete and J.L Tadeo, 2003. Intl. J. Chromatography A., 1007: 137-143.

[147] Furusawa, N., 2005. J. Chromatographia., 62: 315-318

[148] Dong, C., Z. Zeng and X. Li, 2005. Intl.J. Talanta., 66: 721-727.

[149] Wang, J., L. Tuduri, M. Mercury, M. Millet, O. Briand and M. Montury, 2009. Intl. J. Environmental Pollution., 157: $365-370$.

[150] Zeng, J., J. Chen, Y. Wang,W. Chen, Xi Chen and X. Wang, 2008. Intl. J. Chromatography A., 1208: 34-41.

[151] Corte's-Aguado, S., N. Sa'nchez-Morito, F.J. Arrebola, A. Garrido Frenich and J.L. Mart1'nez Vidal, 2008. Intl. J. Food Chemistry., 107: 1314 1325.

[152] Tsoutsi, C., I. Konstantinou, D. Hela and T. Albanis, 2006. Intl. J. Analytica Chimica Acta., 573-574: $216-222$.

[153] V. Casas, V., M. Llompart, C. Garc'1a-Jares, R. Cela and T. Dagnac, 2006. Intl. J. Chromatography A., 1124: 148-156.

[154] Fytianos, K., N. Raikos, G. Theodoridis, Z. Velinova and H. Tsoukali, 2006. J. Chemosphere., 65: 2090-2095.

[155] Tsoukali, H., G. Theodoridis, N. Raikos and I. Grigoratou, 2005. Intl. J. Chromatography B., 822: 194-200.

[156] S'anchez-Ortega, A., M. C. Sampedro, N. Unceta, M. A. Goicolea and R .J. Barrio, 2005. Intl. J. Chromatography A., 1094: 70-76.

[157] Mughari, A. R.,P. P. V'azquez and M. M. Galera, 2007. Intl. J. Analytica Chimica Acta., 593: 157-163.

[158] Sagratini, G., J. Ma nes, D. Giardin'a, P. Damiani and Y. Pic', 2007. Intl. J. Chromatography A., 1147: 135-143.

[159] Campillo, N., R. Pe nalver and M. Hern'andez-C'ordoba, 2007. Intl. J. Talanta., 71: 1417-1423.

[160] X. Xu, H. Yang, L. Wang, B. Han, X. Wang and Frank S. C. Lee, 2007. Intl. J. Analytica Chimica Acta.,591: 87-96.

[161] Gonz'alez, B. E., E. C. Grãna, A. Guimaraes, C. Gonc, alves, S. M. Lorenzo and M.F. Alpendurada, 2007. Intl. J. Chromatography A., 1141: 165173.

[162] Zambonin, CG., A. Cilenti and F.J. Palmisano, 2002. Intl. J. Chromatography A., 967: 255-260. 